Document downloaded from:

http://hdl.handle.net/10251/60664

This paper must be cited as:

Ponz Tienda, JL.; Pellicer Armiñana, E.; Benlloch Marco, J.; Andrés Romano, C. (2015). The Fuzzy Project Scheduling Problem with Minimal Generalized Precedence Relations. Computer-Aided Civil and Infrastructure Engineering. 30(11):872-891. doi:10.1111/mice.12166.

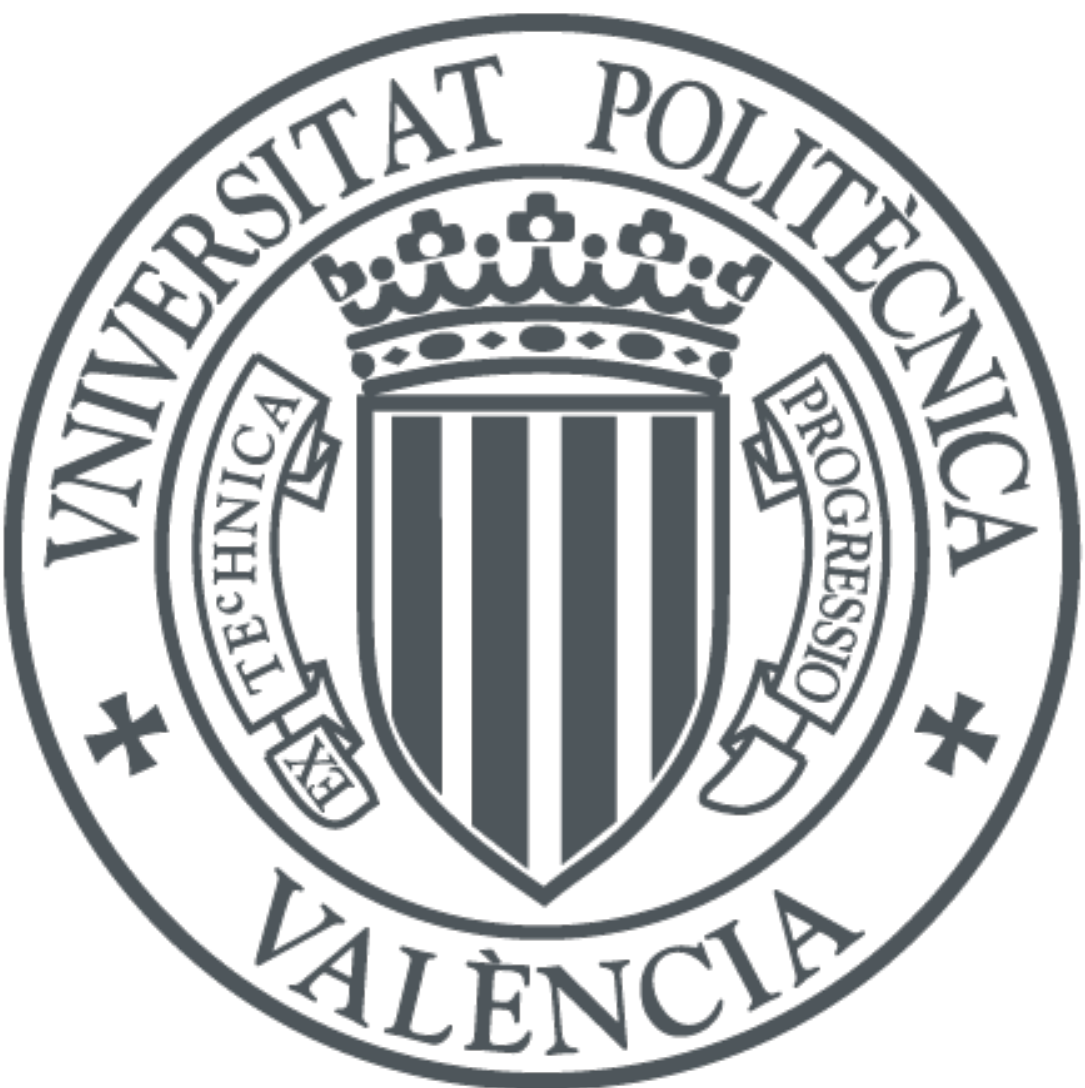

The final publication is available at

http://dx.doi.org/10.1111/mice.12166

Copyright Wiley

Additional Information 


\title{
Fuzzy Project Scheduling Problem with Minimal Generalized Precedence Relations
}

\author{
José Luis Ponz-Tienda \\ Universidad de Los Andes, Carrera 1 Este No. 19A-40, Bogotá, Colombia \\ $\&$ \\ Eugenio Pellicer ${ }^{1}$ Javier Benlloch-Marco Carlos Andrés-Romano \\ Universitat Politècnica de València, Camino de Vera s/n, 46022 Valencia, Spain
}

\begin{abstract}
In scheduling, estimations are affected by the imprecision of limited information on future events, and the reduction in the number and level of detail of activities. Overlapping of processes and activities requires the study of their continuity, along with analysis of the risks associated with imprecision. In this line, this paper proposes a fuzzy heuristic model for the Project Scheduling Problem with flows and minimal feeding, time and work Generalized Precedence Relations with a realistic approach to overlapping, in which the continuity of processes and activities is allowed in a discretionary way. This fuzzy algorithm handles the balance of process flows, and computes the optimal fragmentation of tasks, avoiding the interruption of the critical path and reverse criticality. The goodness of this approach is tested on several problems found in the literature; furthermore, an example of a 15-story building was used to compare the better performance of the algorithm implemented in Visual Basic for Applications (Excel) over that same example input in Primavera $\odot$ P6 Professional V8.2.0, using five different scenarios.
\end{abstract}

Keywords: activity splitting; fuzzy; generalized precedence relations; process flow; project scheduling; reverse criticality.

\section{INTRODUCTION}

Construction projects are developed under the constraints of scope, time and budget. To achieve the time target, including interim deadlines, construction schedulers generally use a group of tools known as the critical path method, scheduling through a hierarchy of three layers from low to high levels of detail (Nicholas \& Steyn, 2008). This cascade structure implies that for short-term planning, the growth in the level of detail increases the number of activities with simple interdependences between them; however, long-term planning implies that, on the one hand, the number of activities is reduced but, on the other hand, complex interdependences with overlapping and decisions on continuity of the activities are generated (Arditi \& Bentotage, 1996). The proposal presented later in the paper helps schedulers dealing with this issue.

\footnotetext{
To whom correspondence should be addressed:

Eugenio Pellicer, Associate Professor

School of Civil Engineering,

Universitat Politècnica de València (Spain)

E-mail: pellicer@upv.es
}

The problem of overlapping and splitting the activities was studied for first time by Crandall (1973), who considered that disallowing the splitting of activities was an excessive relaxation of the real problem; he proposed a novel algorithm with discretional fragmentation. After Crandall, several authors (Wiest, 1981) (Valls, Martí, \& Lino, 1996) (Moder, Philips, \& Davis, 1983) have proposed different improvements to Crandall's algorithm but, to the best of the authors' knowledge, the problem of the overlapping and optimal fragmentation of activities is not totally solved yet. Furthermore, some of the activities of construction projects are grouped in processes (Hejducki, 2004) that cannot be addressed in the traditional way: the decision is not focused on the fragmentation of the activities but on the continuous execution (flow) between them throughout the process.

Additionally, long-term planning involves unavailable or incomplete information, which requires rough estimations in the forecast of project parameters, producing a high risk of failure (Nicholas \& Steyn, 2008) (Ballesteros-Pérez, González-Cruz, \& PastorFerrando, 2010) (Herroelen \& Leus, 2005). To solve the problem of risk management in projects, statistical approaches have been proposed such as the Program Evaluation Review Technique (Malcolm, Roseboom, Clark, \& Fazar, 1959), or the Monte Carlo Simulation Models based on random distributions (Alarcón, Ashley, Sucre de Hanily, Molenaar, \& Ungo, 2011).

Several authors argue that when the nature of the risk is associated not with the presence of random variables but with the imprecision of the estimates produced by limited information (Bonnai, Gourc, \& Lacoste, 2004) (Herroelen \& Leus, 2005), the use of the Theory of Fuzzy Sets is appropriate (Zadeh, 1965). Lootsma (1989) states that the Theory of Fuzzy Sets is closer to reality and simpler to use than stochastic models, facilitating the implementation of values that are not precisely known, but that can be limited within certain bounds of membership or fuzziness (Castro-Lacouture, Süer, Gonzalez-Joaqui, \& Yates, 2009). In natural linguistic terms, when there is not sufficient information for a deterministic estimation or a statistical measurement, experts use their own judgment and experience with the available project information, with expressions such as "approximately" or "around" a minimum and a maximum value, in other words, "more-or-less" (Haque Khan \& Akhtar Hasin, 2012). 
Summarizing, available mathematical models for practitioners in construction scheduling and planning do not consider the actual complex and imprecise conditions of projects (Castro-Lacouture, Süer, Gonzalez-Joaqui, \& Yates, 2009), challenging decisions on discretional splitting of activities and continuity of processes. Therefore, in order to partially fill this gap, the authors propose a heuristic approach to the Project Scheduling Problem with Generalized Precedence Relationships applying the Theory of Fuzzy Sets, which allows the optimal splitting of activities and considers the processes flow. This way, this research contributes to the body of knowledge of construction project scheduling in two facets: (a) using fuzzy sets theory; and (b) implementing the splitting of activities and flow of processes. This approach takes into account the sometimes unavoidable interruption of activities at the construction site, improving other previously proposed algorithms, as well as the commercial software, and providing robust results. Furthermore, the use of fuzzy logic provides a friendlier environment for the practitioner than stochastics approaches.

In order to introduce this proposal properly, the following section provides a literature review of the state-of-knowledge of the Project Scheduling Problem with Generalized Precedence Relationships (GPSP from now on). Section 3 details the proposed model for the fuzzy Project Scheduling Problem with Generalized Precedence Relationships (fuzzy-GPSP hereafter) with flows and minimal generalized relationships for production planning in construction projects. In section 4, sound examples found in literature are solved in different ways to check the goodness and versatility of the fuzzy-GPSP. An example of application is displayed in Section 5 in order to prove that the model can be rigorously implemented to assist practitioners; the fuzzy-GPSP is compared to Primavera $(c)$ P6 Professional V8.2.0 in diverse scenarios presenting the differences and performance metrics. Finally, conclusions and limitations of the research are drawn.

\section{LITERATURE REVIEW}

The classical scheduling methods of Activity-OnArrow graphs, such as the Critical Path Method (Kelley \& Walker, 1959) and the Program Evaluation Review Technique (Malcolm, Roseboom, Clark, \& Fazar, 1959), were developed simultaneously at the end of the 50 's by two separate organizations (the DuPont and

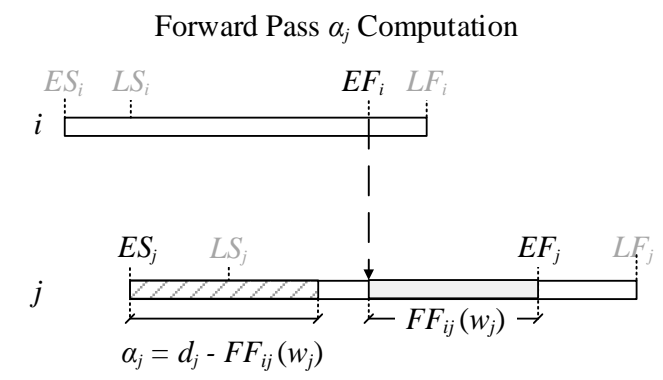

Remington Rand and the US navy with Polaris missile project respectively). They introduced the concept of precedence in a finish-to-start relationship $\left(F S_{i j}(z)\right)$ in which activity $j$ (successor) cannot start until activity $i$ (predecessor) is totally finished. The times of each activity are computed by applying a forward-backward algorithm in a topologically ordered graph. Times obtained in the forward pass (ascending order) are known as the earliest starting time $\left(E S_{j}\right)$ and the earliest finishing time $\left(E F_{j}\right)$ of the activities, establishing the duration of the project (makespan) as the earliest finishing time of the last activity. When the algorithm is applied in descending order (backward pass), the latest starting $\left(L S_{j}\right)$ time and the latest finishing $\left(L F_{j}\right)$ time of the activities are obtained.

In addition to the classical finish-to-start relationship ( $\left.F S_{i j}(z)\right)$ of the Activity-On-Arrow (Fondahl, 1961), more Generalized Precedence Relations (GPRs) applying Activity-On-Node graphs were proposed by Kerbosch and Schell (1975), IBM (1968) and Crandall (1973). The first authors (Kerbosch \& Schell, 1975) proposed the so-called Extended METRA Potential Method, developed in France in 1958 (Roy, 1962), introducing for the first time the notion of "percentage relation for the begin-begin (start-to-start) relation". IBM (1968) and Crandall (1973) developed the Precedence Diagramming Method with GPRs as currently known. The new GPRs for the Precedence Diagramming Method are the start-to-start $\left(S S_{i j}(z)\right)$, the finish-to-finish $\left(F F_{i j}(z)\right)$ and the start-to-finish ( $\left.S F_{i j}(z)\right)$ relationships.

Both methods, the Extended METRA Potential Method and the Precedence Diagramming Method, seem to be similar but are conceptually different. The Extended METRA Potential Method only computes the earliest starting and finishing times, considering activities as "no splitting allowed". Crandall (1973) considered that disallowing the splitting of activities is an excessive relaxation of the real problem, and presented a complete heuristic algorithm to compute the times for the activities and the minimum duration of the project. The algorithm is capable of recognizing the segments ( $\alpha \& \beta$ ) (see Fig 1 ) belonging to the same activity and the decision of splitting the activities is discretionary for practitioners.

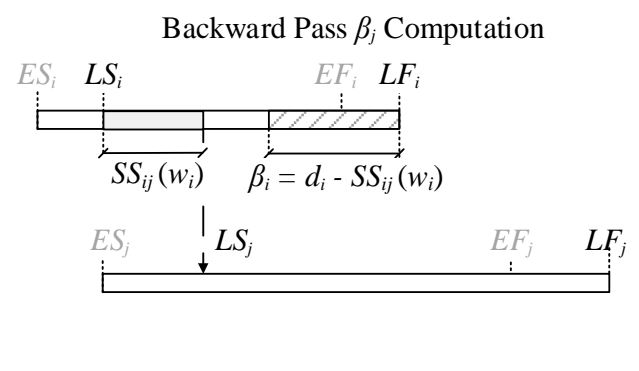


Crandall's algorithm was improved by Moder et al. (1983), including the start-to-finish relationship. More recently, Valls et al. (1996) analyzed Crandall's algorithm and the splitting criteria failures, proposing a new computation for the splitting parameters, as well as a new and more realistic treatment of the start-to-finish relationship; they considered simultaneously two different values for $z$, concerning its predecessor and successor, respectively. Another algorithm was proposed by Hajdu (1996), which involved relaxing the splitting criteria without considering the $\alpha \& \beta$ segments.

For the "no splitting allowed" problem, the GPRs can be relaxed into the more familiar finish-to-start relations (Elmaghraby \& Kamburowski, 1992) (standardized form), or into minimum start-to-start precedence relations (Bartusch, Möhring, \& Radermacher, 1988) (De Reyck \& Herroelen, 1998; 1999). If more than one relationship exists between $i$ and $j$, only the most restrictive must be considered. Unfortunately, in some cases, these relaxations provide infeasible solutions to the problem.

The Precedence Diagramming Method with GPRs presents anomalous effects that are counterintuitive about the consequences of lengthening or shortening a job (Wiest, 1981) (Herbert \& Deckro, 2011) (Valls \& Lino, 2001), changing the concept of the critical path itself. This anomalous effect, called "reverse criticality", is produced when a critical path passes through an activity from finish to start. Then, the activity's effect on the critical path is "perverse" (Crandall, 1973), i.e., lengthening the activity shortens the critical path and shortening the activity lengthens the path; consequently, such a result is called a reverse criticality. Reverse criticality occurs because the $z$ value of the relationships is usually a function of the intensity in the execution of the activities; this aspect is not covered in the traditional formulation (Herbert \& Deckro, 2011).

Another approach considers the use of artificial neural networks in order to optimize the scheduling problem, taking the neural dynamics model of Adeli and Park (1995) for structural optimization as its point of departure. Adeli \& Karim (1997; 2001), Karim \& Adeli (1999a; 1999b), Adeli \& Wu (1998), and Senouci \& Adeli (2001) considered precedence relationships, repetitive and non-repetitive activities, work continuity, multiple crews, as well as the effect of changing job conditions on the performance of a crew in their scheduling models. All these models were based on the time-cost trade-off, seeking minimizing cost as well as time optimization.

Other approaches considerer the intensity of the activities using the "feeding precedence" constraints (Kis, Erdös, \& Márkus, 2004) (Kis, 2005; 2006), based on the model developed by Leachman et al (1990) with overlapping execution of activities. The Leachman dependences were classified by Bianco and Caramia (Bianco \& Caramia, 2009; 2011; 2012) as $\%$ Completed-to-start (\%CS) and additional feeding precedences are the Start-to-\%Completed (S\%C), Finish-to-\%Completed (F\%C) and \%Completed-toFinish (\%CF). To solve the partial overlap and fragmentation of activities, Kis (2006) proposed the manual splitting of activities, introducing appropriate precedence constraints.

More recently, new approaches were proposed in order to face the problem of overlapped activities: Beeline Diagramming Method (Kim, 2012), Design Structure Matrix (Srour, Abdul-Malak, Yassine, \& Ramadan, 2013) and Concurrency Scheduling (Lim, Yi, Lee, \& Arditi, 2014). The Beeline Diagramming Method represents the overlapping relationship of two activities with an arrow that indicates the direction of workflow, from any point of the predecessor to any point of the successor; it allows multiple linkage relationships between two activities, providing more realistic schedules in a hierarchy schedule (Kim, 2012). The Design Structure Matrix model, based on the work of Krishnan, Eppinger \& Whitney (1997), finds the shortest possible (overlapped) design schedule by processing the dependence information gathered in the exchange among design activities. Concurrency-based scheduling keeps makespan and cost down by overlapping the predecessors and the successors without assigning additional resources, characterizing the activities by two attributes: evolution as the production rate of a predecessor activity, and sensitivity as the probability of rework's occurrence in the successor when a change occurs in the predecessor (Lim, Yi, Lee, \& Arditi, 2014).

The problem of the Repetitive Scheduling Method, i.e. repetitive activities organized in processes, has been deeply studied since O’Brien (1969) proposed the Line of Balance for projects of multi-story buildings, houses, and highways or pipelines (Damci, Arditi, \& Polat, 2013). This method is widely accepted under different names as the Vertical Production Method (O'Brien, 1975), Linear Scheduling Method (Barrie \& Paulson, 1978) (Adeli \& Karim, 1997) (Ammar, 2013), TimeSpace Scheduling Method (Stradal \& Cacha, 1982), or Repetitive Scheduling Method (Harris \& Ioannou, 1988) (Maravas \& Pantouvakis, 2011); currently, it is more well-known as Location-Based Scheduling (Seppänen, Evinger, \& Mouflard, 2014).

The first works applying fuzzy logic to project scheduling problem was by Prade (1979) and Chanas \& Kamburowski (1981) applying fuzzy numbers with triangular membership functions based on optimistic, the most likely, and the pessimistic estimates of the respective activity durations. Chang, Tsujimura, Gen, \& Tozawa (1995) proposed a project planning based on fuzzy Delphi method, and Chen \& Chang (2001) dealt with the problem of finding Multiple Possible Critical Paths using Fuzzy PERT.

One of the most controversial problems on fuzzy scheduling is the problem of ranking (Brunelli \& Mezei, 2013) (Deng, 2014) (Wang, Yang, Xu, \& Chin, 2006) and determining latest starting dates in a satisfactory manner. Dubois, Fargier, \& Galva (2003) 
dealt with the problem of determining latest starting dates and slack times in a satisfactory manner (Chanas \& Kamburowski, 1981) (Rommelfanger, 1994) (Dubois, Fargier, \& Galva, 2003). Chen \& Huang (2007) proposed a method to measure the fuzzy criticality in project network. Castro-Lacouture et al. (2009) applied fuzzy values to time, cost, and material restrictions using fuzzy mathematical models. PonzTienda, Pellicer, \& Yepes (2012) proposed a fuzzy scheduling model integrating a novel interpretation of Earned Value Indexes. The latest proposal was by Chrysafis \& Papadopoulos (2014) with an alternative approach to Fuzzy-PERT based on possibilistic estimate for the mean to avoid the problem of the backward recursion.

Approaches applying robust optimization models were proposed by Long \& Ohsato (2006). Shi and Blomquist (2012) and Maravas and Pantouvakis (2011; 2011b) proposed fuzzy durations for activities considering overlapping. The first authors (Shi \& Blomquist, 2012) used the fuzzy Design Structure Matrix, indexing the time factor of information exchange along with the durations for each activity and their relationships in two different matrices: one for the predecessor activities and the other for the successor activities. The second authors (Maravas \& Pantouvakis, 2011) applied the fuzzy Repetitive Scheduling Method for the scheduling of repeating activities whose unit production rates were uncertain or imprecise. Finally, Ma, Gu, \& Li (2015) suggested a scenario-based proactive robustness optimization method, which aims to improve the soundness of construction project schedules that are developed using the critical chain project management method.

Throughout the analyzed literature, researchers have shown that the GPRs are needed to formulate "real-life constraints" (Schwindt, 2014), and that fragmentation and overlapping of processes and activities is very effective in improving the estimation of the project makespan for the Unconstrained PSP (Valls, Martí, \& Lino, 1996) (Ponz-Tienda, Benlloch-Marco, AndrésRomano, \& Gil-Senbre, 2011) and Constrained PSP (Quintanilla, Pérez, Lino, \& Valls, 2012), as well as for fast-tracking complex construction projects (Srour, Abdul-Malak, Yassine, \& Ramadan, 2013) by setting up overlapping activities (Lim, Yi, Lee, \& Arditi, 2014). Pre-emption as a solution for the fragmentation has been widely studied in manufacturing and services environments. Nonetheless, realistic approaches to the optimal splitting and overlapping of activities and processes in construction projects with imprecise values for durations and relationships is almost void (Lino, Pérez, Quintanilla, \& Valls, 2012) and still open for research (Schwindt, 2014).

Several scheduling techniques have been briefly presented in this section, but available mathematical models and decision support systems for practitioners hardly take into account the complex and ill-defined conditions of construction projects. Karim \& Adeli (1999c) stated that "the limitations and shortcomings of the existing software systems used in practice are also recognized by the construction industry” (p. 381); however, the traditional CPM approach "is still being used despite its documented shortcomings, particularly for projects involving repeating tasks" (Karim \& Adeli, 1999c) (p. 380). Therefore, in order to partially fill this gap and make a contribution to the body of knowledge, the authors propose in the next section a heuristic approach to the fuzzy Project Scheduling Problem with Generalized Precedence Relationships allowing the optimal splitting of activities and considering the processes flow.

\section{THE PROPOSED FUZZY-GPSP FOR PRODUCTION PLANNING IN CONSTRUCTION PROJECTS.}

For the purpose of this research, an activity is defined as a unique and basic work entity which consumes a certain quantity of resources with a constant intensity during its execution; an activity can be carried out by parts (Lopez \& Roubellat, 2013). A process is defined as a set of $P$ repetitive activities (called cycles) that must be executed strictly one after the other but not necessarily in a continuous way; they consume the same quantity of resources with a constant intensity during their execution.

The formulation of the proposed model for the Unconstrained GPSP is based on the following principles: (a) the activities of the project can be fragmented in a discretionary way according to the criteria of the practitioner; (b) under a functional point of view, a maximum of one interruption point per activity is considered (Valls, Martí, \& Lino, 1996); and (c) the activities belonging to the same process must be executed without interruption and with discretional continuity between them, according to the criteria of the practitioner (Fig. 2). In real environments, activities and processes interact with each other, transmitting information in the form of "minimum production flows", which are necessary for the occurrence of future events in the successor activities and/or processes.
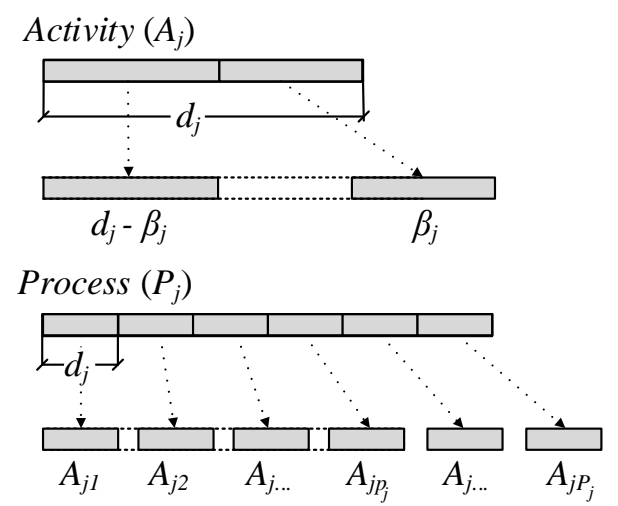

Fig. 2 Splitting criteria of Processes and Activities

Before presenting the model, the traditional subtraction in the backward pass of the fuzzy-PSP needs to be explained to avoid further confusion. Computing the latest times (LS) of the activities is an important issue which can provide negative values for the left side of the obtained fuzzy number. This happens because the 
backward pass of the pseudo-code 1 is strictly applied as with crisp values, without taking the precaution that computing the $L S$ of the activities is calculated by solving an equation with the $L S$ as the unknown term (Eq. 1):

$$
L S_{i}+\operatorname{Dur}_{i}=L F_{i} \rightarrow L S_{i}=L F_{i}-D r_{i}
$$

This fact does not have transcendental implications on scheduling with crisp values, but with fuzzy values the equation must be solved as a Minkowski's subtraction (Buckley \& Eslami, 2002) (Chrysafis \& Papadopoulos, 2014) of the supports of the fuzzy number (Eq. 2), guarantying that the obtained solution is always culminate in an positive confidence interval (Gil-Aluja, 2004). If a fuzzy difference is applied, negative values can be obtained for the times of the activities, providing incorrect solutions:

$$
\begin{gathered}
\overline{L S}_{i}(x) \oplus \overline{\operatorname{Dur}}_{i}(x)=\overline{L F}_{i}(x) \\
\left(l s_{i 1}, l s_{i 2}, l s_{i 3}\right) \oplus\left(d_{i 1}, d_{i 2}, d_{i 3}\right)=\left(l f_{i 1}, l f_{i 2}, l f_{i 3}\right) \\
\left\{\begin{array}{l}
l s_{i 1}=\min \left(l s_{i 2}, l f_{i 1}-d_{i 1}\right) \\
l_{s_{i 2}}=l f_{i 2}-d_{i 2} \\
l s_{i 3}=\max \left(l s_{i 2}, l f_{i 3}-d_{i 3}\right)
\end{array}\right.
\end{gathered}
$$

In the model introduced in this paper, the criteria for computing the times of the activities is an evolution of Crandall's proposal (1973), including the Valls et al. (1996) start-to-finish relationship, with a different formulation for determining the splits of the activities and the Latest Starting (LS) times, which avoid unfeasible solutions providing optimal project makespan. The proposed algorithm is based on establishing the value of the fragment $\beta_{j}$ in two phases.

In the first phase, $\beta_{j}$ is initialized as the minimum "work/feeding GPR" restriction that affects the finishing of the activity (Eq. 3). Once the times of the successors are computed, $\beta_{j}$ is recomputed in a second phase (Fig. 3), as the minimum feasible value that meets the constraints of the problem, applying Eq. 4.

$$
\beta_{j}=\min \left(F F_{i j} \mid S F_{i j}\right), \forall i \text { sucessor of } j
$$

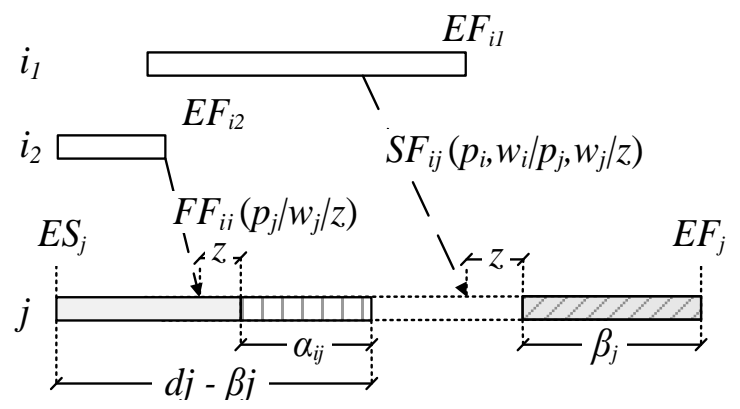

Fig. 3 Computing the fragment $\beta_{j}$

$$
\begin{gathered}
E F_{i} \leq E S_{j}-d_{j}-\beta_{j} \rightarrow\left\{\begin{array}{l}
\text { True } \rightarrow \alpha_{i j}=d_{j}-E F_{i}-E S_{j}-\beta_{j} \\
\text { False } \rightarrow \alpha_{i j}=0
\end{array}\right. \\
\beta_{j}=\max \left(\beta_{j}, p_{j} \cdot d_{j}+w_{j}-\alpha_{i j}\right)
\end{gathered}
$$

The possible relationships between activities and processes are explained in the following paragraphs, with the criteria and pseudo-code for determining the times.
The finish-to-start $\left(F S_{i j}(z)\right)$ precedence relationship between activities (or activities-processes) (Fig. 4) represents the minimum number of $z$ "time units" that must elapse between the completion of the predecessor activity, $A_{i}$, and the start of the follower activity, $A_{j}$ (or activity $A_{j p}$ of the process $P_{j}$ ).

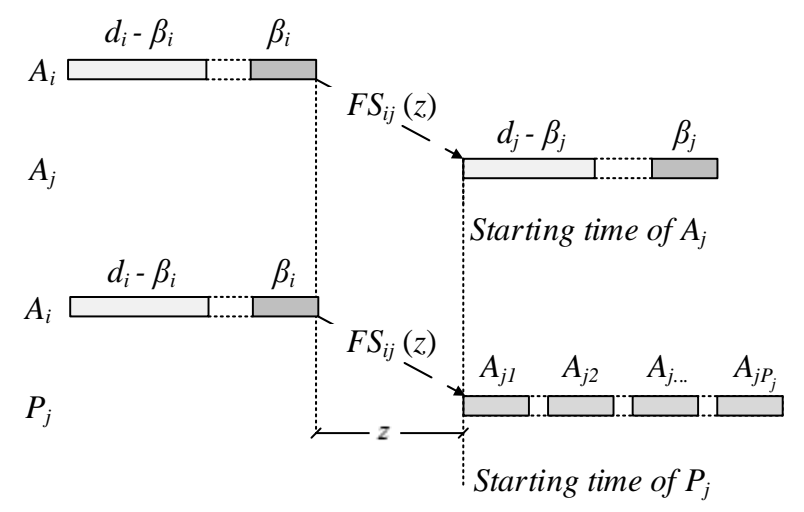

Fig. 4 Finish-to-start $\left(\overline{F S}_{i j}(\mathrm{z})\right)$ relationship between activities and activities-processes

The pseudo-code to compute the times for the fuzzy finish-to-start $F S_{i j}(\bar{z}(x))$ precedence relationship is presented in Pseudo-code 1:

\begin{tabular}{c}
\hline Pseudo-code 1: fuzzy FS relationship \\
\hline Early Times \\
\hline CASE predecessor $(i) \rightarrow$ successor $(j)$ OF \\
Case activity $(i) \rightarrow$ activity $(j):$ \\
{$\left[E S_{j}\right]^{\alpha}=\overline{\max }\left(\left[E S_{j}\right]^{\alpha},\left[E F_{i}\right]^{\alpha} \oplus[z]^{\alpha}\right)$} \\
{$\left[E F_{j}\right]^{\alpha}=\overline{\max }\left(\left[E F_{j}\right]^{\alpha},\left[E S_{j}\right]^{\alpha} \oplus\left[d_{j}\right]^{\alpha}\right)$} \\
Case activity $(i) \rightarrow$ process $(j):$ \\
{$\left[E S_{j 1}\right]^{\alpha}=\overline{\max }\left(\left[E S_{j 1}\right]^{\alpha},\left[E F_{i}\right]^{\alpha} \oplus[z]^{\alpha}\right)$} \\
{$\left[E F_{j 1}\right]^{\alpha}=\left[E S_{j 1}\right]^{\alpha} \oplus\left[d_{j}\right]^{\alpha}$} \\
CALL FrWComputeProccessesTimes $(j, 2)$ \\
END CASE \\
\hline Latest Times \\
CASE predecessor $(i) \rightarrow$ successor $(j)$ OF \\
Case $a c t i v i t y(i)-a c t i v i t y(j):$ \\
{$\left[L F_{i}\right]^{\alpha}=\overline{\min }\left(\left[L F_{i}\right]^{\alpha},\left[L S_{j}\right]^{\alpha}-[z]^{\alpha}\right)$} \\
{$\left[L S_{i}\right]^{\alpha}=\overline{\min }\left(\left[L S_{i}\right]^{\alpha},\left[L F_{i}\right]^{\alpha}-\left[d_{i}\right]^{\alpha}\right)$} \\
Case activity $(i) \rightarrow$ process $(j):$ \\
CALL BckWComputeProccessesTimes $(j, 1)$ \\
{$\left[L F_{i}\right]^{\alpha}=\overline{\min }\left(\left[L F_{i}\right]^{\alpha},\left[L S_{j 1}\right]^{\alpha}-[z]^{\alpha}\right)$} \\
{$\left[L S_{i}\right]^{\alpha}=\overline{\min }\left(\left[L S_{i}\right]^{\alpha},\left[L F_{i}\right]^{\alpha}-\left[d_{i}\right]^{\alpha}\right)$}
\end{tabular}

\section{END CASE}

Note: the arithmetic operator - is the traditional (not fuzzy) subtraction operator (Eq. 2)

The feeding/work \& time start-to-start ( $\left.S_{i j}\left(p_{i}\left|w_{i}\right| z\right)\right)$ precedence relationship between activities (or activities-processes) (Fig. 5) represents the minimum number of $p_{i} \cdot d_{i}$ or/and $w_{i}$ "work units" 
$\left(0 \leq p_{i}<1, w_{i}<d_{i}\right)$ required on the predecessor activity, $A_{i}$, prior to the start of the successor activity, $A_{j}$ (or process $P_{j}$ ), with an additional lag of $z$ "time units".
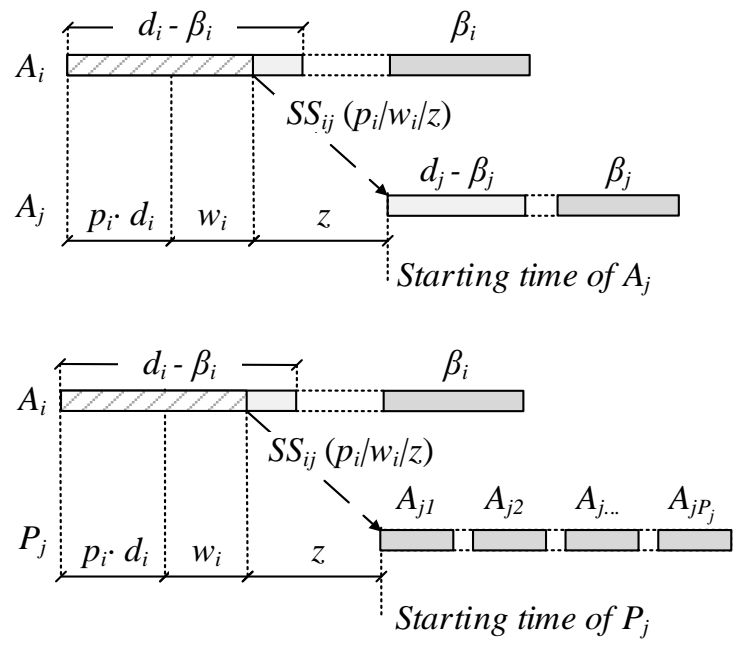

Fig. 5 Feeding/work \& time start-to-start $\left(S_{i j}\left(p_{i}\left|w_{i}\right| z\right)\right)$

\author{
$A_{i}$
}

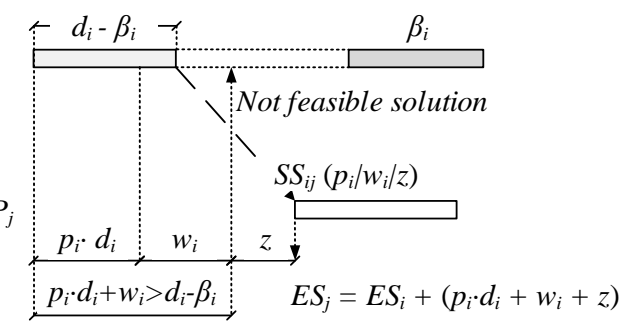

$A_{i}$

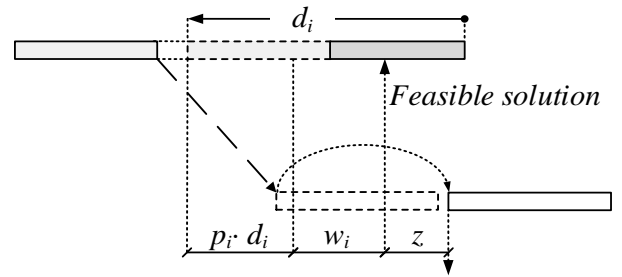

$E S_{j}=E F_{i}-d_{i}+\left(p_{i} \cdot d_{i}+w_{i}+z\right)$

Fig. 6 Feasible / not feasible solution for the $S_{i j}\left(p_{i}\left|w_{i}\right| z\right)$

In the forward pass for computing the earliest starting ( $E S_{j}$ ) times of the successor activity or process, it is necessary to verify the feasibility of the solution when the predecessor activity is to be split. When $p_{i} \cdot d_{i}+w_{i}>d_{i}-\beta_{i}$, the minimum production flow required for starting the successor is not met, so it is necessary to delay the starting time of the successor ( $A_{j} / P_{j}$ ) to a feasible position from the finishing time of the predecessor $\left(A_{i}\right)$, as can be seen in the right side of Fig. 6.

The Pseudo-code 2 is presented to compute the times for the fuzzy start-to-start $S_{i j}\left(\bar{p}_{i}(x)\left|\bar{w}_{i}(x)\right| \bar{z}(x)\right)$ precedence relationship, including a new computation for the Latest Starting times based on a parameter $k_{i j}$ :

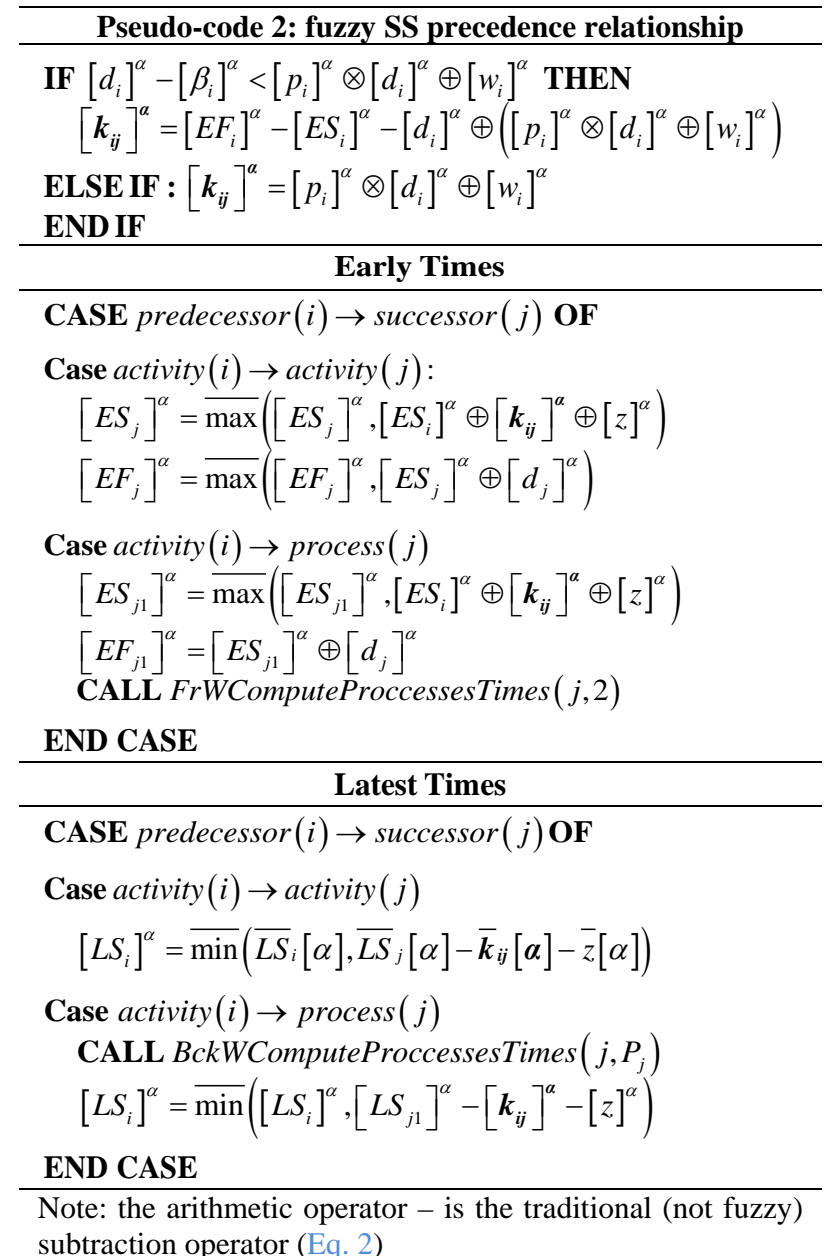
subtraction operator (Eq. 2)

\section{The feeding/work \& time finish-to-finish}

$\left.F F_{i j}\left(p_{j}\left|w_{j}\right| z\right)\right)$ precedence relationship between activities (Fig. 7) represents the minimum number of $p_{j} \cdot d_{j}$ or/and $w_{j}$ "work units" $\left(0 \leq p_{j}<1, w_{j}<d_{j}\right)$ required on the follower activity, $A_{j}$, after the completion of its predecessor, $A_{i}$, with an additional lag of $z$ "time units".

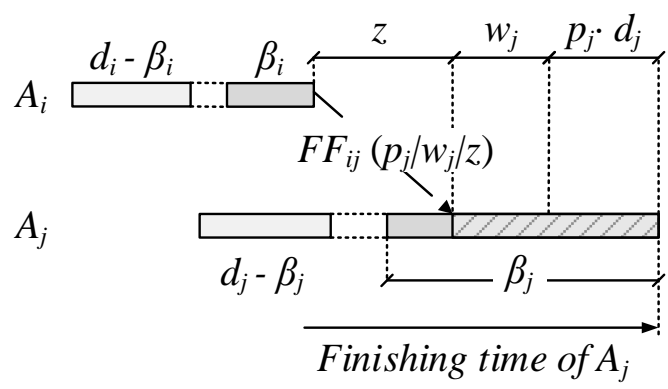

Fig. 7 Feeding/work \& time finish-to-finish $\left(F F_{i j}\left(p_{j}\left|w_{j}\right| z\right)\right)$

The Pseudo-code 3 is presented to compute the times for the fuzzy finish-to-finish $F F_{i j}\left(\bar{p}_{j}(x)\left|\bar{w}_{j}(x)\right| \bar{z}(x)\right)$ precedence relationship:

\begin{tabular}{l}
$\frac{\text { Pseudo-code } 3 \text { fuzzy FF precedence relationship }}{\text { Early Times }}$ \\
\hline$[\text { aux }]^{\alpha}=\left[E F_{i}\right]^{\alpha} \oplus\left[p_{j}\right]^{\alpha} \otimes\left[d_{j}\right]^{\alpha} \oplus\left[w_{j}\right]^{\alpha} \oplus[z]^{\alpha}$ \\
{$\left[E F_{j}\right]^{\alpha}=\overline{\max }\left(\left[E F_{j}\right]^{\alpha},[\text { aux }]^{\alpha}\right)$}
\end{tabular}




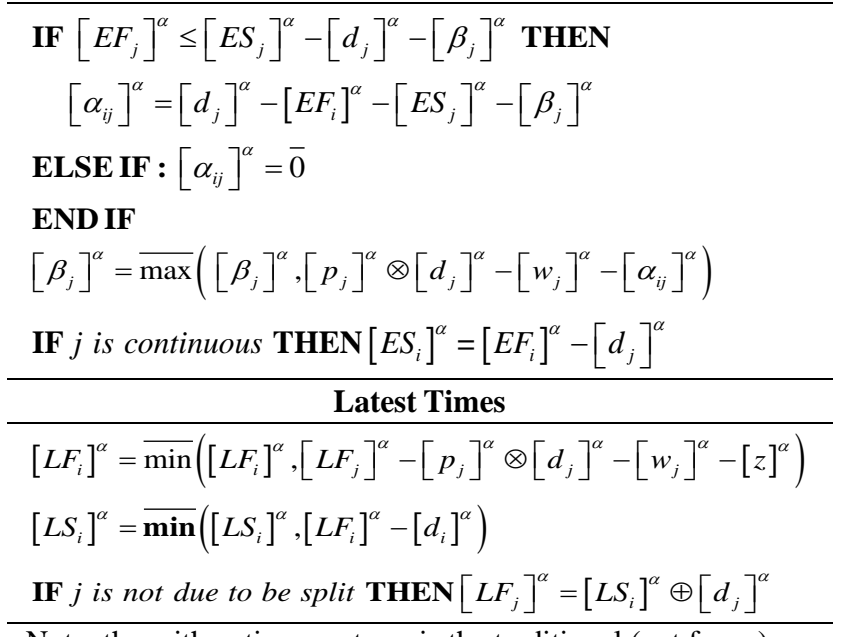

Note: the arithmetic operator - is the traditional (not fuzzy) subtraction operator (Eq. 2)

\section{The feeding/work \& time start-to-finish (} $\left.S F_{i j}\left(p_{i}, w_{i}\left|p_{j}, w_{j}\right| z\right)\right)$ precedence relationship between activities (Fig. 8) represents the minimum number of $p_{j} \cdot d_{j}$ or/and $w_{j}$ "work units" $\left(0 \leq p_{j}<1, w_{j}<d_{j}\right)$ required on the follower activity, $A_{j}$, after the minimum number of $p_{i} \cdot d_{i}$ or/and $w_{i}$ "work units" ( $0 \leq p_{i}<1, w_{i}<d_{i}$ ) on the predecessor activity, $A_{i}$, has been completed, with an additional lag of $z$ "time units".
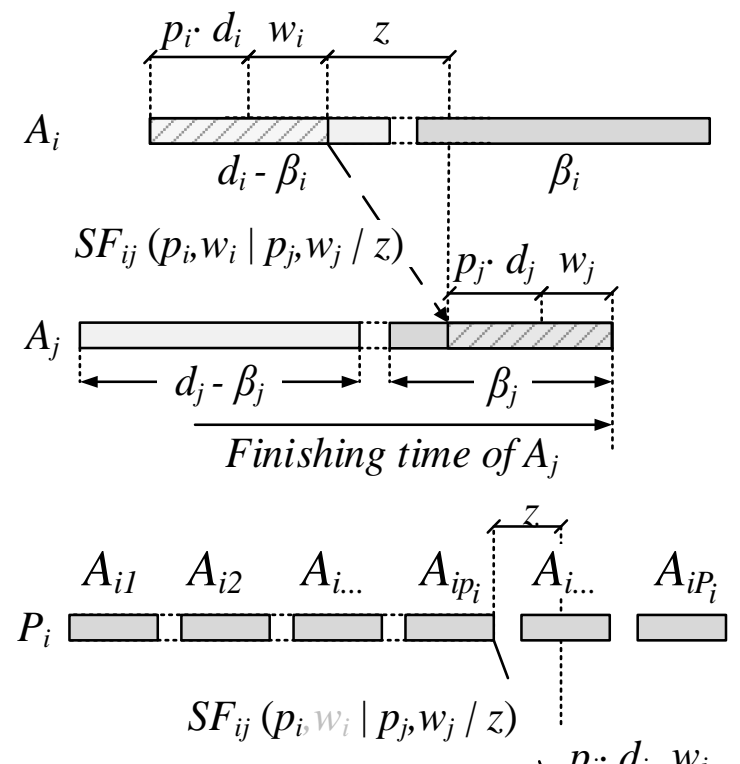

$A_{j}$

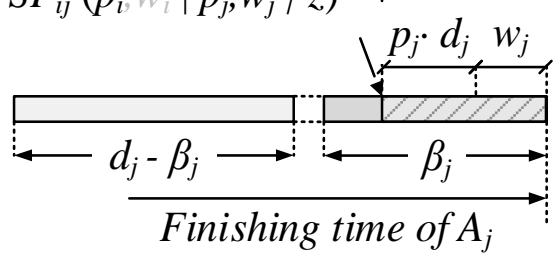

Fig. 8 Feeding/work \& time start-to-finish $\left(S_{i j}\left(p_{i}, w_{i}\left|p_{j}, w_{j}\right| z\right)\right)$

This approach for the start-to-finish relationship ( $\left.S F_{i j}\left(p_{i}, w_{i}\left|p_{j}, w_{j}\right| z\right)\right)$ is based on the formulation proposed by Valls et al. (1996), and suits a greater diversity of conditions more closely to reality. The traditional formulation $\left(S F_{i j}(z)\right)$ only considers the units required between the finish of the activity and the start of the predecessor; this fact implies the paradox, in production terms, that a follower activity can finish without a "real start" of the predecessor.

The procedure to compute the times for the fuzzy finish-to-finish $S F_{i j}\left(\bar{p}_{i}(x), \overline{\mathrm{w}}_{i}(x)\left|\bar{p}_{j}(x), \bar{w}_{j}(x)\right| \bar{z}(x)\right)$ precedence relationship is presented in the Pseudo-code 4.

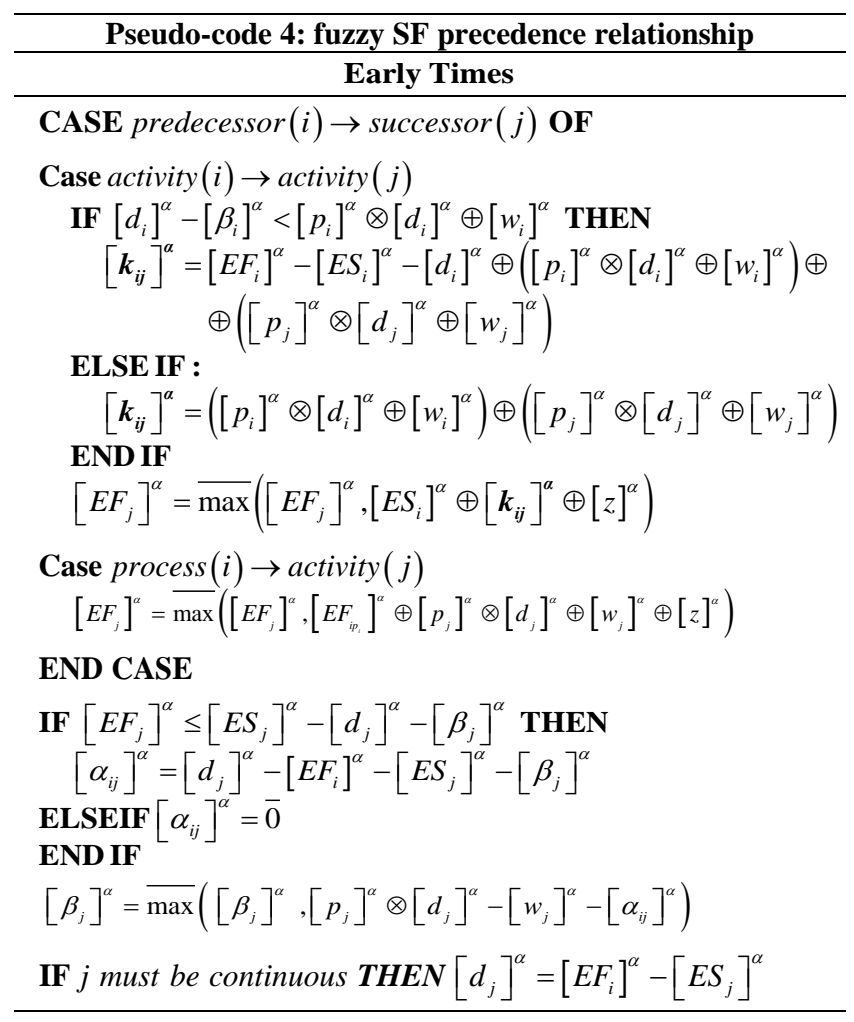

\section{Latest Times}

CASE predecessor $(i) \rightarrow$ successor $(j)$ OF

Case $\operatorname{activity}(i) \rightarrow \operatorname{activity}(j)$

$$
\begin{aligned}
& {\left[L F_{i}\right]^{\alpha}=\overline{\min }\left(\left[L F_{i}\right]^{\alpha},\left[L F_{j}\right]^{\alpha}-\left[\boldsymbol{k}_{i j}\right]^{\alpha}-[z]^{\alpha}\right)} \\
& {\left[L S_{i}\right]^{\alpha}=\overline{\min }\left(\left[L S_{i}\right]^{\alpha},\left[L F_{i}\right]^{\alpha}-\left[d_{i}\right]^{\alpha}\right)}
\end{aligned}
$$

Case $\operatorname{process}(i) \rightarrow \operatorname{activity}(j)$

$$
\begin{aligned}
& {\left[L F_{i p_{i}}\right]^{\alpha}=\overline{\min }\left(\left[L F_{i p_{i}}\right]^{\alpha},\left[L F_{j}\right]^{\alpha}-[z]^{\alpha}\right)} \\
& {\left[L S_{i p_{i}}\right]^{\alpha}=\overline{\min }\left(\left[L S_{i p_{i}}\right]^{\alpha},\left[L F_{i p_{i}}\right]^{\alpha}-\left[d_{i}\right]^{\alpha}\right)} \\
& \text { CALL BckWComputeProccessesTimes }\left(i, p_{i}\right)
\end{aligned}
$$

\section{END CASE}

Note: the arithmetic operator - is the traditional (not fuzzy) subtraction operator (Eq. 2)

The flow \& time $\left(F l_{i j}\left(p_{i}\left|p_{j}\right| z\right)\right)$ relationship between processes or activity-processes (Fig. 9) represents the minimum number of $p_{i}$ cycles (or $p_{i} \cdot d_{i}$ ) required on the predecessor process, $P_{i}$ (or activity $A_{i}$ ), prior to the starting of process $P_{j}$, with an additional lag of $z$ "time units". This formulation for the flow \& time relationship is and adaptation of the Valls et al. (1996) proposal of the start-to-finish precedence relationship between activities. 

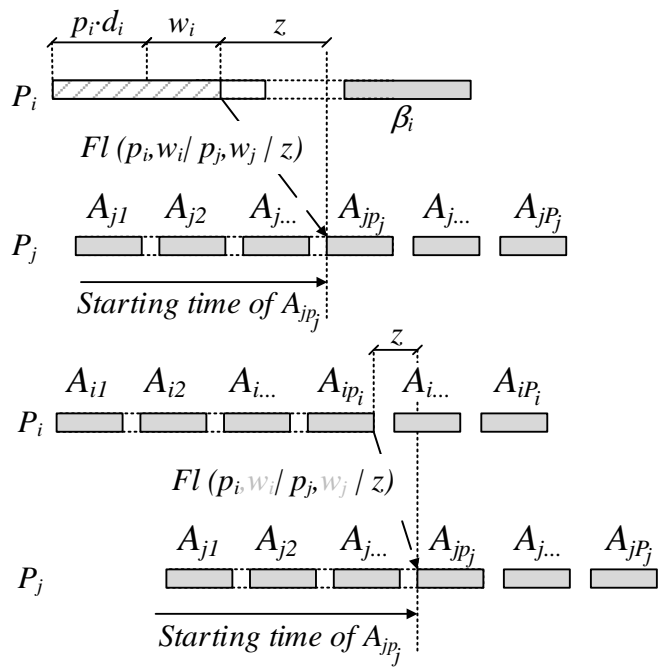

Fig. 9 Flow \& time $\left(F l_{i j}\left(p_{i}, w_{i}\left|p_{j}, w_{j}\right| z\right)\right)$

The algorithm to compute the times for the fuzzy flow ( $\left.\mathrm{Fl}_{i j}\left(\bar{p}_{i}(x), \bar{w}_{i}(x)\left|\bar{p}_{j}(x), \bar{w}_{j}(x)\right| \bar{z}(x)\right)\right)$ relationship is presented in the Pseudo-code 5.

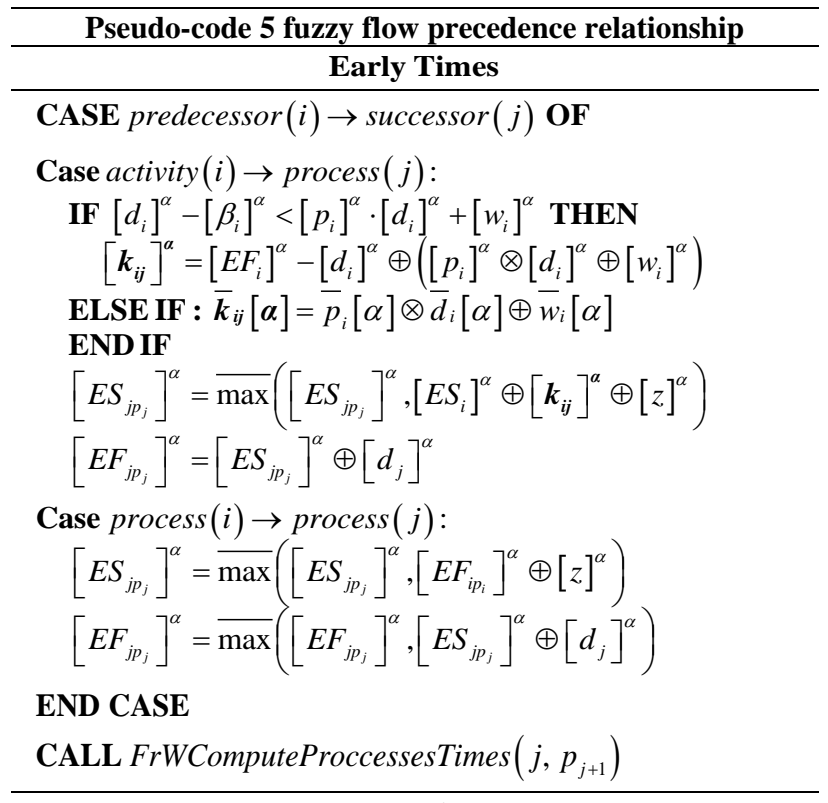

\section{Latest Times}

CALL : BckWComputeProccessesTimes $\left(j, P_{j}\right)$

CASE predecessor $(i) \rightarrow$ successor $(j)$ OF :

Case $\operatorname{activity}(i) \rightarrow \operatorname{process}(j)$

$$
\left[L S_{i}\right]^{\alpha}=\overline{\min }\left(\left[L S_{i}\right]^{\alpha},\left[L S_{j p_{j}}\right]^{\alpha}-\left[\boldsymbol{k}_{i j}\right]^{\alpha}-[z]^{\alpha}\right)
$$

$$
\begin{aligned}
& \text { Case process }(i) \rightarrow \operatorname{process}(j) \\
& {\left[L F_{i p_{i}}\right]^{\alpha}=\overline{\min }\left(\left[L F_{i p_{i}}\right]^{\alpha},\left[L S_{j p_{j}}\right]^{\alpha}-[z]^{\alpha}\right)} \\
& {\left[L S_{i p_{i}}\right]^{\alpha}=\overline{\min }\left(\left[L L_{i p_{i}}\right]^{\alpha},\left[L F_{i p_{i}}\right]^{\alpha}-\left[d_{i}\right]^{\alpha}\right)}
\end{aligned}
$$

CALL BckWComputeProccessesTimes $\left(i, p_{i}\right)$

\section{END CASE}

Note: the arithmetic operator - is the traditional (not fuzzy) subtraction operator (Eq. 2)

The algorithm for computing the times of the processes in the forward (FrWComputeProcc_Times $\left(j, p_{j}\right)$ ) and backward (BckWComputeProcc_Times $\left(i, p_{i}\right)$ ) pass is shown in pseudo-code 6.

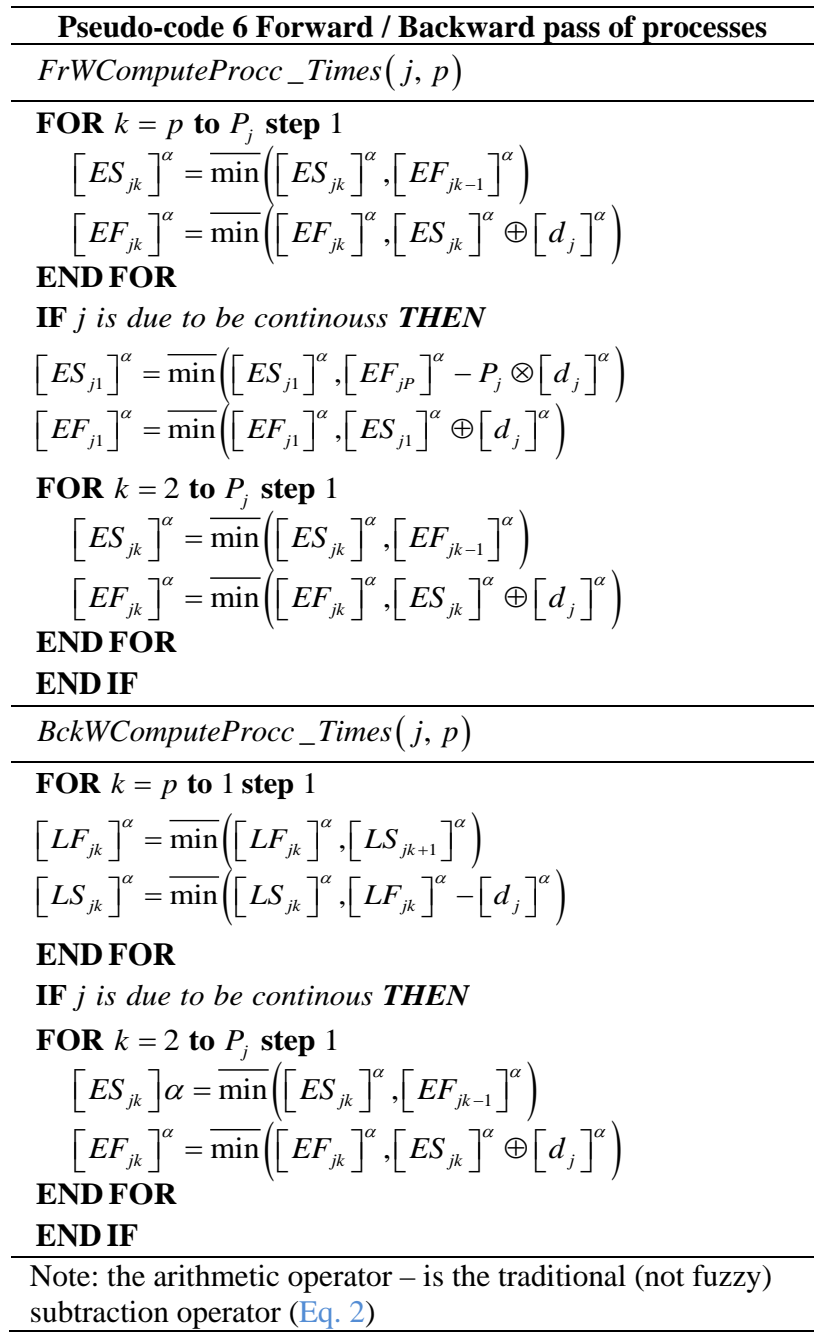

The compiled heuristic algorithm for the fuzzy-GPSP, presented in the pseudo-code 7 , implements pseudocodes 1 to 7 , and summarizes the procedure. The previous step consists in establishing the value for the project starting time ( $\overline{\text { ProjectStart }}(\alpha)$ ), the number of activities/processes, and the interval for the alpha cuts ( alphainterval ), which must be a real number between zero and one $(0 \leq$ alphainterval $\leq 1)$. The proposed algorithm is simpler than the existing ones and corrects the errors that other approaches have, especially by computing the latest times.

Pseudo-code 7 Compiled algorithm for the fuzzy-GPSP
SET $\overline{\text { ProjectStart }}(\alpha)=(0,0,0)$
SET NumberofActivities
SET alphainterval $\mid 0 \leq$ alphainterval $\leq 1$
Phase $0:$ Preliminary $\bar{\alpha})$ computations
FOR alpha $=0$ to 1 step alphainterval
FOR $i=1$ to NumberofActivities step 1
IF predecessor $=$ activity
AND relationship is $\left(F F_{i j}\right.$ OR $\left.S F_{i j}\right)$ THEN
$\left[\beta_{i}\right]^{\alpha}=$ max $\left(\left[p_{j}\right]^{\alpha} \otimes\left[d_{j}\right]^{\alpha}+\left[w_{j}\right]^{\alpha}\right)$
END IF
END FOR
END FOR

Phase 1 : Forward - Pass computations

$\left[E_{1}\right]^{\alpha}=[\text { ProjectStart }]^{\alpha}$ 


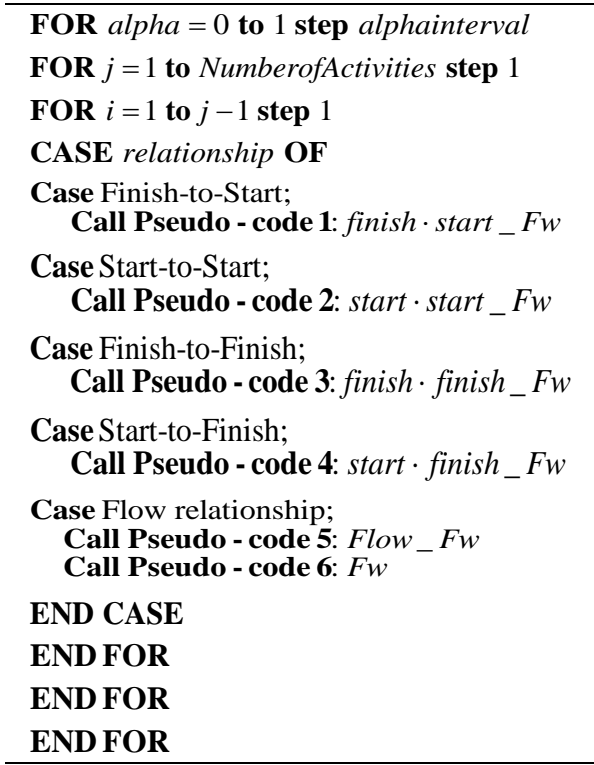

\section{Phase 2 : Backward - Pass computations}

FOR alpha $=0$ to 1 step alphainterval

FOR $i=$ NumberofActivities to 1 step -1

FOR $j=i+1$ to NumberofActivities step 1

CASE relationship OF

Case Finish-to-Start;

Call Pseudo - code 1: start - start_Bw

Case Start-to-Start;

Call Pseudo - code 2: start - start_Bw

Case Finish-to-Finish;

Call Pseudo - code 3 : finish · finish_Bw

Case Start-to-Finish;

Call Pseudo - code 4 : start $\cdot$ finish_Bw

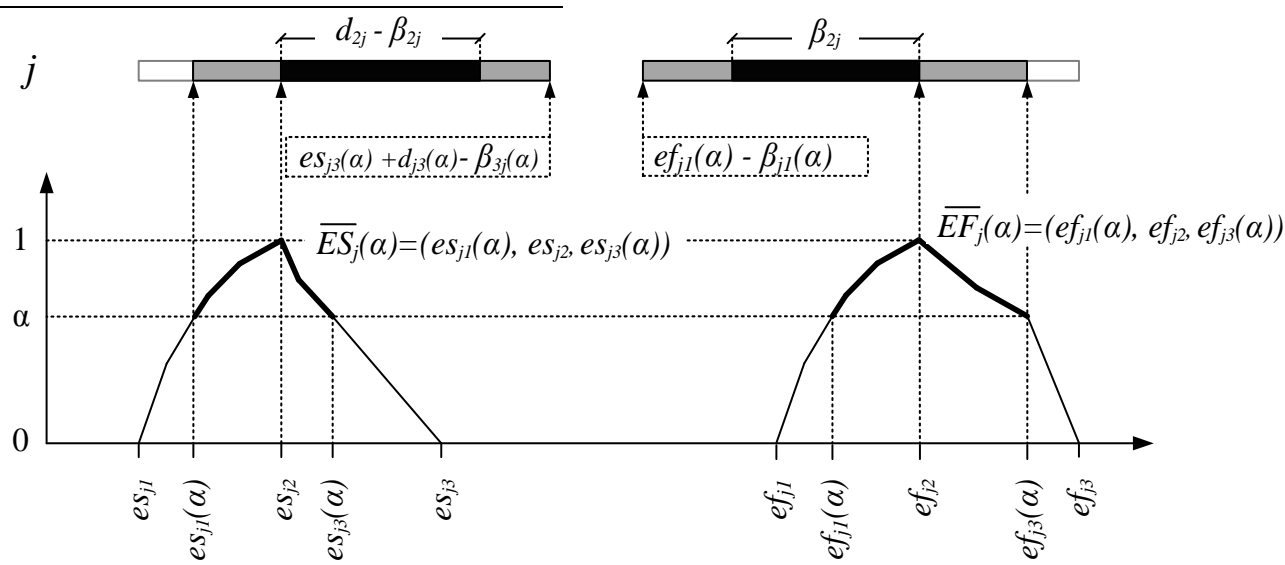

Fig. 10 Interpretation of fuzzy times to build the temporal diagram for a specific alpha cut

The Total Float $(\overline{T F}(x))$ of the activities must be computed in the traditional way (Eq. 5) as the fuzzy difference between the Latest Finishing $(\overline{L F}(x))$ time, the Early Starting $(\overline{E S}(x))$ time and the duration ( $\bar{d}(x))$ of the activities. Additionally, the floats of each one of the fragments of the activities can be computed obtaining the starting $(\overline{s t F}(x))$ (Eq. 6) and finishing ( $\overline{f s F}(x)$ ) floats (Eq. 7) of the activities.

$$
\begin{gathered}
\overline{T F}(x)=\overline{L F}(x) \check{z} \overline{E S}(x) \check{z} \bar{d}(x) \\
\overline{S t F}(x)=\overline{L S}(x) \check{z} \overline{E S}(x) \\
\overline{f S F}(x)=\overline{L F}(x) \check{z} \overline{E F}(x)
\end{gathered}
$$

The fuzziness in the floats enhances the notion of criticality itself, making it possible to rank the activities

Case Flow relationship;
$\quad$ Call Pseudo - code 5: Flow_Bw
Call Pseudo - code 6: $B w$
END CASE
END FOR
END FOR
END FOR

The previous fuzzy values for the earliest starting times $\left[E S_{j}\right]^{\alpha}=\left(e s_{j 1}(\alpha), e s_{j 2}, e s_{j 3}(\alpha)\right)$ and the earliest finishing times $\left[E F_{j}\right]^{\alpha}=\left(e f_{j 1}(\alpha)_{j}, e f_{j 2}, e f_{j 3}(\alpha)\right)$ of the activities must be interpreted as depicted in Fig. 10, based on the values of $\left[\beta_{j}\right]^{\alpha}=\left(\beta_{j 1}(\alpha)_{j}, \beta_{j 2}, \beta_{j 3}(\alpha)\right)$. In order to build the temporal diagram on its latest times, the earliest starting times $\left[E S_{j}\right]^{\alpha}$ and the earliest finishing times $\left[E F_{j}\right]^{\alpha}$, they must be changed by the latest starting time $\left[L S_{j}\right]^{\alpha}=\left(l s_{j 1}(\alpha), l s_{j 2}, l s_{j 3}(\alpha)\right)$ and the latest finishing times $\left[L F_{j}\right]^{\alpha}=\left(I f_{j 1}(\alpha), l f_{j 2}, l f_{j 3}(\alpha)\right)$, respectively.

in different degrees of criticality through the Critical Index $\left(C I_{j}\right)$ and the Critical Value $\left(C V_{j}\right)$ which established the criticism degree and the risk of criticality respectively.

In this way, an activity belongs totally to the set of critical activities (membership equal to 1 ) if the vertex of the fuzzy float is zero $\left(f_{j 2}=0\right)$. When the vertex of the fuzzy float is a positive value $\left(f_{j 2}>0\right)$ and the left support is a negative value $\left(f_{j 1} \leq 0\right)$, the activity is only critical for certain degrees of vagueness from zero to the Critical Index $\left(C I_{j}\right)$. The Critical Index $\left(C I_{j}\right)$ is the value of the alpha cut for which all the values of the float's subset are greater than zero (Eq. 8 and Fig. 11). 
Values near to one represent more criticality than values near to zero.

$$
\begin{gathered}
\forall \bar{F}_{j}(x)=\left(f_{j 1} \leq 0, f_{j 2}>0, f_{j 3}>0\right) \exists C I_{j} \mid \\
{\left[F_{j}\right]^{C I_{j}}=\left[f_{j 1}\left(C I_{j}\right), f_{j 3}\left(C I_{j}\right)\right]=\left\{C I_{j} \in \square: f_{j 1}\left(C I_{j}\right)=0\right\}}
\end{gathered}
$$

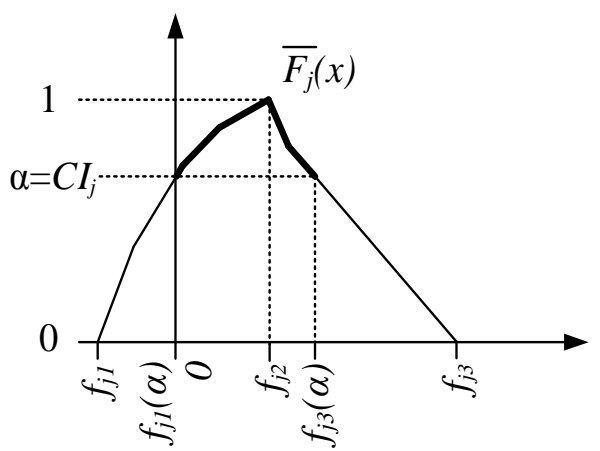

Fig. 11 Critical Index $\left(C I_{j}\right)$

The same value for the Critical Index $\left(C I_{j}\right)$ can be obtained for infinite shapes with identical vertex and supports of $\bar{F}(x)$ depending on their convexity (Fig. 12), but convex shapes present more risk of criticality than non-convex shapes for the same Critical Index (
$\left.C I_{j}\right)$. The Critical Value $\left(C V_{j}\right)$ establishes the risk of criticality, and is computed by applying Eq. 9 as the relation of areas (left side $\left(S_{1 j}\right)$ between right side ( $S_{2 j}$ ) from zero of the fuzzy float $(\bar{F}(x))$ multiplied by the Critical Index $\left(C I_{j}\right)$. However, values near to 1 represent more risk of criticality than values near to zero.

$$
C V_{j}=\left(S_{1 j} / S_{2 j}\right) \cdot C I_{j}
$$

In a similar way, the risk of accomplishing the project makespan (Fig. 13) can be computed over the compromise date, establishing the Risk Index $(R I)$ as the relation between the area to the right side of the compromise date and the total area of the fuzzy makespan by applying Eq. 10.

$$
R I=S R_{2} / S R_{1}
$$

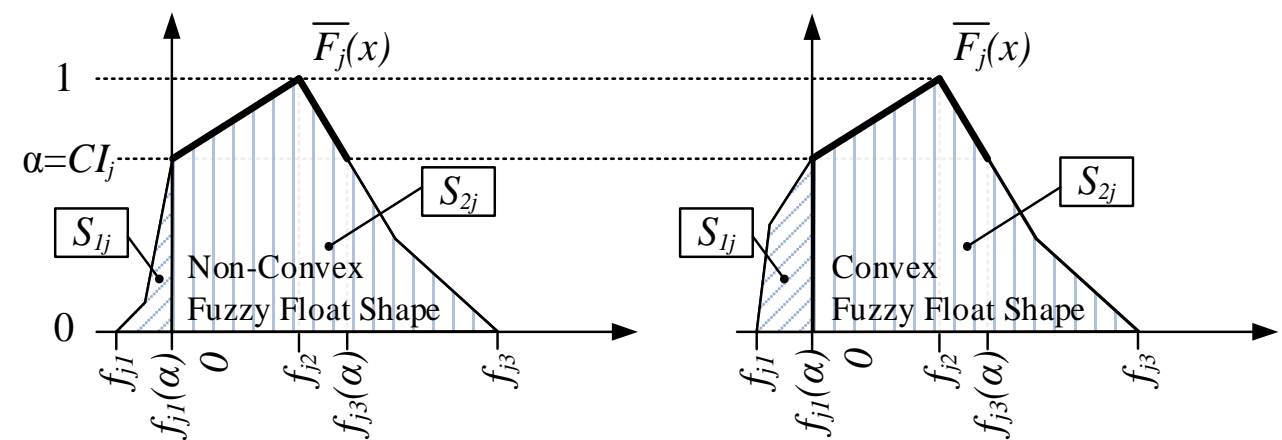

Fig. 12 Critical Value $\left(C V_{j}\right)$

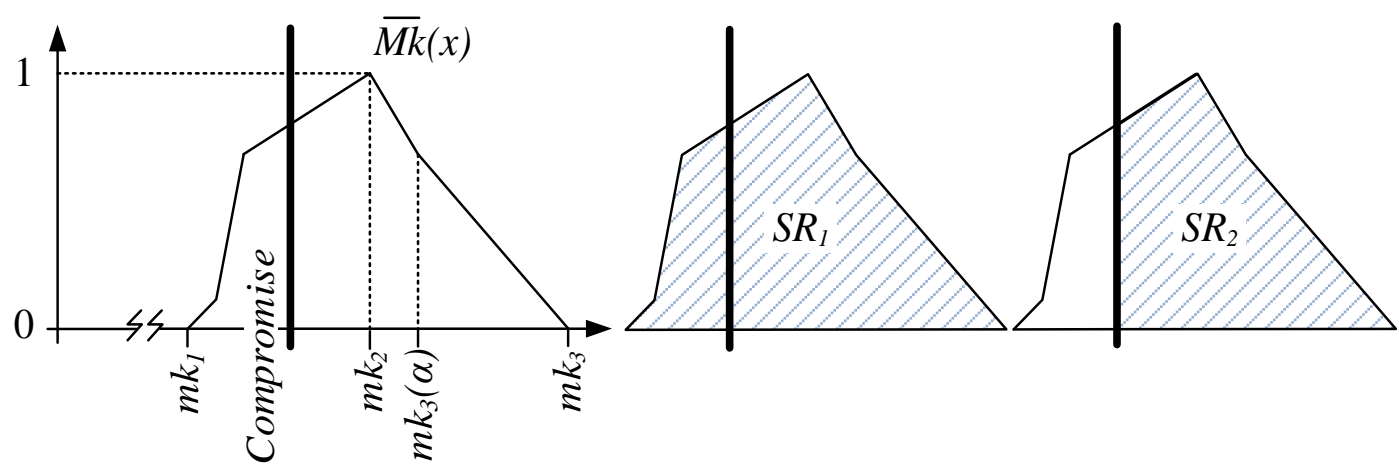

Fig. 13 Risk Index ( $R I$ ) of fuzzy makespan

\section{COMPARISON TO PREVIOUS RELEVANT PROBLEMS}

The proposed fuzzy-GPSP model needs numerical experimentation and comparison to test its reliability. However, libraries cited in the literature for benchmarking (e.g. (Demeulemeester \& Herroelen, 2002) (Valls, Martí, \& Lino, 1996)) are not available for this comparison due that researchers did not explicitly provide them; moreover, the Project Scheduling Problem Library (Kolisch \& Sprecher, 1996) was developed for finish-to-start relationships and does not consider the GPRs. Therefore, the authors follow other approaches. For the numerical experimentation some relevant problems identified in the literature are solved in different ways. These relevant problems were proposed by Crandall (1973), Valls et al. (1996), Maravas and Pantouvakis (2011), Kim (2012), and Shi and Blomquist (2012). They are computed again using the proposed fuzzy-GPSP and the results are compared to the original solution; Table 1 summarizes how each of them considers feeding, work and time GPRs and flow, as well as their main limitations. They are briefly discussed next. 
The Crandall (1973) problem was reproduced and computed with the proposed fuzzy-GPSP algorithm considering "splitting allowed" for all the activities, durations as crisp values, and all the relationships between the activities as "Work GPRs". The problem was solved with the fuzzy-GPSP algorithm, obtaining the same times for the activities. Due to the simplicity of the problem, the goodness of Crandall's proposal was not conclusive. In fact, some failures were detected by Valls et al. (1996), especially on the splitting criteria and the computation of the latest starting $(L S)$ times, which can produce discontinuities in the critical path when criticality is at the beginning and involves the $\beta$ fragment of an activity.

The problem used by Valls et al. (1996) in their research was solved with the following criteria: all the durations are taken as crisp values and the relationships as "Work GPRs". The project makespan and the early times obtained are the same as the original results provided by the authors. However, Valls et al.'s algorithm (1996) is difficult to interpret and implement, presenting some relatively ambiguous aspects such as the criterion for calculating the latest starting $(L S)$ times of the activities. These values are not included in their work and are not entirely consistent with the conclusions obtained by applying their formulation.

The Maravas and Pantouvakis (2011) six-unit repetitive project, presented by Harris \& Ioannou (1988), for testing the fuzzy Repetitive Scheduling Method has been reproduced considering: (1) activity $A$ as three continuous processes $A_{1,2}, A_{3,4}$ and $A_{5,6} ;(2)$ activity $B$ as one splittable process of six activities $\left(B_{1-6}\right)$; (3) activity $C$ as one continuous process of four activities ( $C_{1-4}$ ) and an additional activity $C_{6}$; and (4) activities $\mathrm{E}$ and $\mathrm{F}$ as continuous processes $\left(E_{1-6} / F_{1-6}\right)$. The values obtained when applying fuzzy-GPSP to the problem are the same as those obtained by the authors for the vertex (crisp values), and seem to be the same for the supports of the fuzzy times that are not explicitly stated. The only difference is in activity $B$ because of the discretional interruption between units 3 and 4 ("work break to accommodate the delivery").

The problem used by Kim (2012) for the Beeline Diagramming Method has been solved considering all the activities as "no splitting allowed", durations as crisp values, and transforming all precedence relationships ( $N p-N s$ ) into start-to-start GPRs ( $S S(p=0|w=N p-N s| 0)$ ) when necessary. The results obtained are totally coincident in time and criticality with those presented by the author.

The Shi and Blomquist (2012) problem is the most recent proposal found in the literature, with all the durations as fuzzy values and the relationships as "feeding GPRs". For a proper transformation, the overlapping established by the time factor is transformed into start-to-start relationships (Eq. 11), because they represent the best fit to the nature of the model proposed by the authors:

$$
\begin{gathered}
\left.{S S_{i j}}_{i j} \bar{p}_{i}(x)\left|\bar{w}_{i}(x)\right| \bar{z}(x)\right) \mid \\
\left\{\begin{array}{l}
\bar{p}_{i}(x)=0 \\
\bar{w}_{i}(x)=\overline{S S}_{i j} \otimes\left(\bar{B}_{i j}(x) \otimes \bar{d}_{i}(x)-\left(\bar{C}_{i j}(x) \otimes \bar{d}_{j}(x)\right)\right) \\
\bar{z}(x)=0
\end{array}\right.
\end{gathered}
$$

The differences observed with the Shi and Blomquist (2012) problem are due to the computation of the overlapping established by the times factor. In Eq. 11 the "-" sign is a not fuzzy operation and this interpretation provides more trustworthy values for the supports of the fuzzy times (all values are positives for the times of the activities).

\begin{tabular}{|c|c|c|c|c|c|}
\hline Algorithm & $\begin{array}{l}\text { Feeding } \\
\text { SS,FF,SF }\end{array}$ & $\begin{array}{c}\text { Work } \\
\text { SS,FF,SF }\end{array}$ & $\begin{array}{c}\text { Time } \\
\text { FS,SS,FF,SF }\end{array}$ & $\begin{array}{l}\text { Flow } \\
\text { Fl }\end{array}$ & Limitations \\
\hline Crandall (1973) & $x, x, x$ & $\sqrt{ }, \sqrt{ }, \times$ & $x, x, x, x$ & $x$ & $\begin{array}{l}\text { Splitting criteria } \\
L S \text { computation }\end{array}$ \\
\hline Valls et al. (1996) & $x, x, x$ & $\checkmark, \sqrt{ }, \sqrt{ }$ & $x, x, x, x$ & $x$ & $\begin{array}{c}\text { Complex computation } \\
\text { LS computation } \\
\end{array}$ \\
\hline $\begin{array}{c}\text { Maravas and } \\
\text { Pantouvakis (2011) }\end{array}$ & $x, x, x$ & $x, x, x$ & $\sqrt{ }, \times, \times, \times$ & $\checkmark$ & $\begin{array}{l}\text { Only time FS and flow } \\
\text { relationships }\end{array}$ \\
\hline Kim (2012) & $x, x, x$ & $\sqrt{ }, \times, \times$ & $\sqrt{ }, \times, \times, \times$ & $\checkmark$ & $\begin{array}{c}\text { No splitting allowed } \\
\text { Only FS/SS relationships }\end{array}$ \\
\hline $\begin{array}{l}\text { Shi and Blomquist } \\
(2012) \\
\end{array}$ & $\checkmark, \times, \times$ & $x, x, x$ & $x, x, x, x$ & $x$ & $\begin{array}{c}\text { Only one GPR } \\
\text { Fuzzy arithmetic }\end{array}$ \\
\hline fuzzy-GPSP & $\sqrt{ }, \sqrt{ }, \sqrt{ }$ & $\checkmark, \sqrt{ }, \sqrt{ }$ & $\checkmark, \sqrt{ }, \sqrt{ }, \sqrt{ }$ & $\checkmark$ & --- \\
\hline \multicolumn{6}{|c|}{$\checkmark$ available, $\times$ not available } \\
\hline
\end{tabular}

Table 1 Algorithms: characteristics, limitations and comparison

The algorithms displayed in Table 1 deal with the problem of overlapping in activities and processes. These algorithms are key contributions to the state-ofknowledge of simultaneity and fragmentation. As it can be inferred from Table 1, the proposed fuzzy-GPSP outperforms the others in these five facets: (a) it considers all the feeding GPRs (only the algorithm proposed by Shi and Blomquist (2012) takes into account the SS), avoiding reverse criticality; (b) it allows the use of the four work and time GPRs; (c) it improves Crandall (1973) and Valls et al. (1996) approaches with a new computation of the fragmentation avoiding the interruption of the critical path; (d) it includes the balance of process flows (only 
embraced previously by Maravas and Pantouvakis (2011) and Kim (2012)); and (e) it presents an innovative formulation of fuzzy values for durations and relationships (even though a fuzzy approach was already proposed by Shi and Blomquist (2012), this one is more complete and robust).

\section{EXAMPLE OF APPLICATION}

As an example of implementation of the algorithm, a building of 15 floors is selected. The first three floors are under-ground and the remaining 12 are aboveground. To ensure the constructability of the foundations, the starting of "excavation phase 2" (a splitted activity) requires at least 14 days from the starting of the "water drainage" to guarantee that the water table is controlled. Additionally, the "water drainage" must work without interruption until at least seven floors of the structure is completely finished to offset the water pressure with its weight. This fact implies that the duration of the "water drainage" is unknown and depends on the times of the followers and especially of the structure. The concrete of the foundations is scheduled in three phases, and overlapped with the reinforcement bars. The structure is a process of 15 activities overlapped with the processes of masonry, facades and basements with an additional lag of 12 days for removal of formwork to ensure the proper hardening of the concrete. A total of 18 activities/processes which summarize 78 activities and sub-processes are considered, contemplating the widest possible set of conditions.

The fuzzy values for the durations of the processes/activities, the number of activities by process and the five scenarios analyzed are displayed in Table 2. The nature of the relationships between activities and/or processes is shown in Table 3 .

Table 2 Example: description of activities, continuity and duration

\begin{tabular}{clccccccc}
\hline \multirow{2}{*}{ Code } & \multirow{2}{*}{ Description Process/activity } & \multicolumn{5}{c}{ Continuity Scenarios } & \# of & Duration \\
\cline { 3 - 6 } & & $\# 1$ & $\# 2$ & $\# 3$ & $\# 4$ & $\# 5$ & activities & $\bar{d}\left(d_{1}, d_{2}, d_{3}\right)$ \\
\hline 1 & Previous works & Yes & Yes & Yes & Yes & Yes & 1 & $\mathrm{~d}(3,5,6)$ \\
\hline 2 & Excavations 0.0/-1.0 & Yes & Yes & Yes & Yes & Yes & 1 & $\mathrm{~d}(12,12,14)$ \\
\hline 3 & Water drainage & Yes & Yes & Yes & Yes & Yes & 1 & Dependent \\
\hline 4 & Diaphragm-wall & Yes & Yes & Yes & Yes & Yes & 1 & $\mathrm{~d}(45,45,50)$ \\
\hline 5 & Excavations & Yes & Yes & Yes & Yes & Yes & 1 & $\mathrm{~d}(28,30,35)$ \\
\hline 6 & Rebars for foundation works & Yes & Yes & Yes & Yes & Yes & 1 & $\mathrm{~d}(15,18,20)$ \\
\hline 7 & Concrete foundation Ph.1 & Yes & Yes & Yes & Yes & Yes & 1 & $\mathrm{~d}(1,1,3)$ \\
\hline 8 & Concrete foundation Ph.2 & Yes & Yes & Yes & Yes & Yes & 1 & $\mathrm{~d}(1,1,3)$ \\
\hline 9 & Concrete foundation Ph.3 & Yes & Yes & Yes & Yes & Yes & 1 & $\mathrm{~d}(1,1,3)$ \\
\hline 10 & Structure & Yes & Yes & Yes & Yes & Yes & 15 & $\mathrm{~d}(11,12,14)$ \\
\hline 11 & Decks & No & No & No & No & Yes & 1 & $\mathrm{~d}(10,15,25)$ \\
\hline 12 & Masonry works & No & No & No & Yes & Yes & 12 & $\mathrm{~d}(3,4,5)$ \\
\hline 13 & Facades & No & Yes & No & No & Yes & 12 & $\mathrm{~d}(6,7,8)$ \\
\hline 14 & Basements & No & No & No & No & Yes & 3 & $\mathrm{~d}(25,30,35)$ \\
\hline 15 & Paving works & No & No & Yes & No & Yes & 12 & $\mathrm{~d}(5,6,8)$ \\
\hline 16 & Office works & No & No & No & No & Yes & 12 & $\mathrm{~d}(10,11,12)$ \\
\hline 17 & Reworks \& finishing & No & No & No & No & Yes & 1 & $\mathrm{~d}(25,35,45)$ \\
\hline 18 & Delivery/reception & Yes & Yes & Yes & Yes & Yes & 1 & $\mathrm{~d}(1,1,1)$ \\
\hline & & & & & & & \\
\hline
\end{tabular}

Table 3 Relationships between processes and activities

\begin{tabular}{|c|c|c|c|c|c|}
\hline \multirow{2}{*}{ Code } & \multirow{2}{*}{ Description } & \multicolumn{4}{|c|}{ Predecessor } \\
\hline & & $\# 1$ & $\# 2$ & $\# 3$ & $\# 4$ \\
\hline 1 & Previous works & -- & & & \\
\hline 2 & Excavations $0.0 /-1.0$ & $\mathrm{FS}_{1-2}(\mathrm{z})$ & & & \\
\hline 3 & Water drainage & $\mathrm{FS}_{2-3}(\mathrm{z})$ & $\mathrm{SF}_{11-3}(\mathrm{p}, \mathrm{w}, \mathrm{z})$ & & \\
\hline 4 & Diaphragm-wall & $\mathrm{FS}_{2-4}(\mathrm{z})$ & & & \\
\hline 5 & Excavations & $\mathrm{SS}_{3-5}(\mathrm{p}, \mathrm{w}, \mathrm{z})$ & $\mathrm{FS}_{4-5}(\mathrm{z})$ & & \\
\hline 6 & Rebars for foundation works & $\mathrm{FS}_{5-6}(\mathrm{z})$ & & & \\
\hline 7 & Concrete foundation Ph.1 & $\mathrm{SS}_{6-7}(\mathrm{p}, \mathrm{w}, \mathrm{z})$ & & & \\
\hline 8 & Concrete foundation Ph.2 & $\mathrm{SS}_{6-8}(\mathrm{p}, \mathrm{w}, \mathrm{z})$ & $\mathrm{FS}_{7-8}(\mathrm{z})$ & & \\
\hline 9 & Concrete foundation Ph.3 & $\mathrm{FS}_{6-9}(\mathrm{z})$ & $\mathrm{FS}_{8-9}(\mathrm{z})$ & & \\
\hline 10 & Structure & $\mathrm{FS}_{9-10}(\mathrm{z})$ & & & \\
\hline 11 & Decks & $\mathrm{FS}_{10-11}(\mathrm{z})$ & & & \\
\hline 12 & Masonry works & $\mathrm{Fl}_{10-12}\left(\mathrm{p}_{\mathrm{i}}, \mathrm{p}_{\mathrm{j}}, \mathrm{z}\right)$ & & & \\
\hline
\end{tabular}




\begin{tabular}{llclll}
\hline 13 & Facades & $\mathrm{Fl}_{10-13}\left(\mathrm{p}_{\mathrm{i}}, \mathrm{p}_{\mathrm{j}}, \mathrm{z}\right)$ & & & \\
\hline 14 & Basements & $\mathrm{Fl}_{10-14}\left(\mathrm{p}_{\mathrm{i}}, \mathrm{p}_{\mathrm{j}}, \mathrm{z}\right)$ & & & \\
\hline 15 & Paving works & $\mathrm{Fl}_{12-15}\left(\mathrm{p}_{\mathrm{i}}, \mathrm{p}_{\mathrm{j}}, \mathrm{z}\right)$ & & & \\
\hline 16 & Office works & $\mathrm{Fl}_{13-16}\left(\mathrm{p}_{\mathrm{i}}, \mathrm{p}_{\mathrm{j}}, \mathrm{z}\right)$ & $\mathrm{Fl}_{15-16}\left(\mathrm{p}_{\mathrm{i}}, \mathrm{p}_{\mathrm{j}}, \mathrm{z}\right)$ & & \\
\hline 17 & Reworks \& finishing & $\mathrm{Fl}_{14-17}\left(\mathrm{p}_{\mathrm{i}}, \mathrm{p}_{\mathrm{j}}, \mathrm{z}\right)$ & $\mathrm{Fl}_{16-17}\left(\mathrm{p}_{\mathrm{i}}, \mathrm{p}_{\mathrm{j}}, \mathrm{z}\right)$ & $\mathrm{FF}_{14-17}(\mathrm{p}, \mathrm{w}, \mathrm{z})$ & $\mathrm{FF}_{16-17}(\mathrm{p}, \mathrm{w}, \mathrm{z})$ \\
\hline 18 & Delivery/reception & $\mathrm{FS}_{17-18}(\mathrm{z})$ & & & \\
\hline
\end{tabular}

The example of application of the proposed fuzzy- proposal (Fig. 14). This application can be downloaded GPSP algorithm has been implemented in Visual Basic from http://goo.gl/VZR0Ta, and allows anyone to for Applications (Excel 2013) (Ponz-Tienda, Yepes, modify the values for the fuzzy times, the type of Pellicer, \& Moreno-Flores, 2013) for a proper relationships, the release date and the continuity of comprehension of the versatility and goodness of the activities and processes.

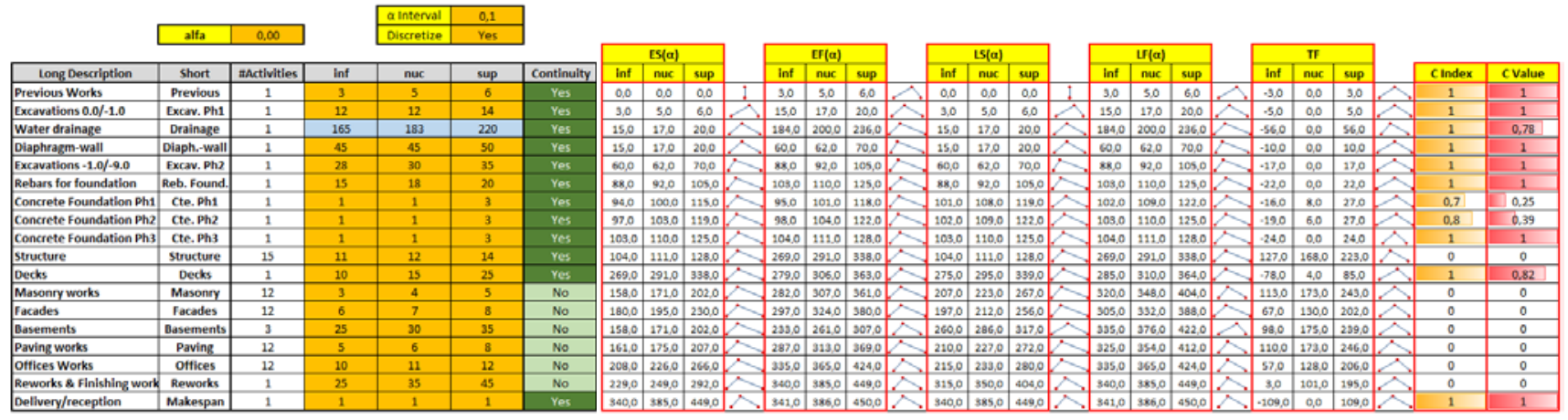

Fig. 14 Implementation of the fuzzy-GPSP algorithm in Visual Basic for Applications (Excel 2013)

The app computes the fuzzy times, fuzzy floats, critical index, and critical value of activities and processes. It also calculates the risk of accomplishing the project makespan over the release date, and plots the fuzzy time for any of the activities by their ES, EF, LS, and LF (Fig. 15 and Fig. 16). Additionally, it permits changes in the precision of the computations modifying the alphainterval, and the discretization of the fuzzy times in real days. The app has been partially implemented with C\# to test the CPU time required to compute the fuzzy times and floats obtaining a mean of $6.67 \cdot 10^{-5}$ seconds for a problem with 35 activities and 10 alpha cuts using an Intel ${ }^{\circledR}$ Core $^{\mathrm{TM}}$ i7-4770 processor at $3.40 \mathrm{GHz}$ and $8 \mathrm{~Gb}$ (RAM).

The example of application included in the app has been solved for five different scenarios with the same compromise date (415 days) and values for durations and relationships. In scenario \#1, activities 1 to 10 and 18 are considered as no splitting allowed, processes 12 to 16 as no continuous, and activities 11 and 17 as splitting allowed obtaining the fuzzy makespan represented in the Fig.15 ( $R I=27.96 \%)$. In scenario \#2, process 13 (Facades) has been changed to continuous, increasing the $R I$ of accomplishment up to $74.38 \%$ (Fig.16) given that the relation between the area to the right side of the compromise date (red line in Fig.15 and Fig.16) and the total area is bigger in scenario \#2 (Fig.16) than in scenario \#1 (Fig.15). In scenarios \#3 and \#4, process 15 (paving works) and process 12 (masonry works) are considered continuous respectively; for scenario \#3, the fuzzy makespan is (357.0, 399.0, 450.0) and the $R I$ is $43.83 \%$; for scenario \#4 the fuzzy makespan increases to (379.0, 421.0, 483.0 ) and the $R I$ to $85.87 \%$. Finally, in scenario \#5, all the activities and processes are considered continuous. The metrics obtained for the fuzzy makespan, Risk Index $(R I)$, sum of the Critical Index $\left(\Sigma C I_{i}\right)$, Critical Value $\left(\Sigma C V_{i}\right)$, and fuzzy Total Float $\left(\sum \overline{T F}_{i}\right)$ of all processes and activities are shown in Table 4.

Table 4 Performance metrics of the example of application

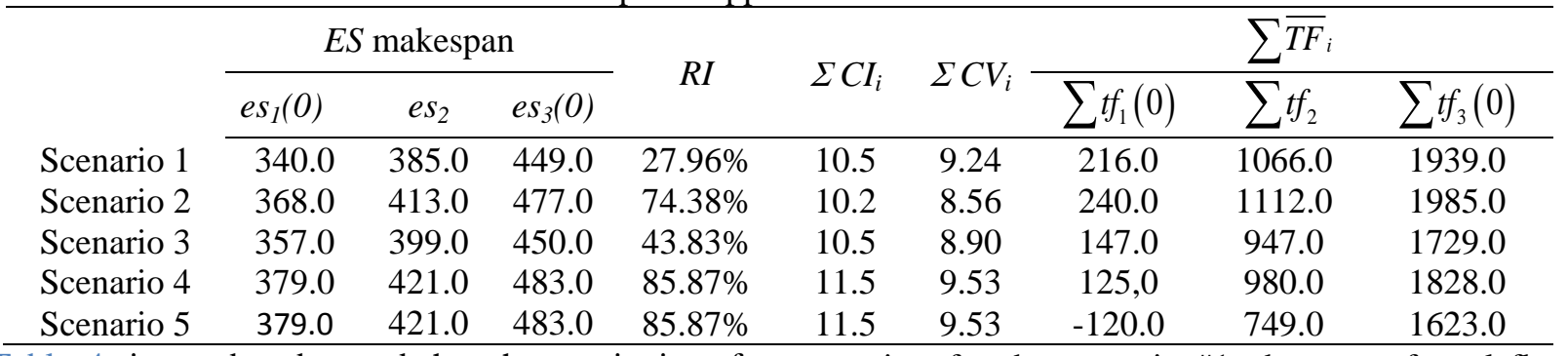

In Table 4, it can be observed that the continuity of processes and activities usually increases the makespan of the project from $(340.0,385.0,449.0)$ for the scenario \#1 to $(379.0,421.0,483.0)$ in scenarios \#4 and $\# 5$, and the risk of accomplishment from $27.96 \%$ (scenario \#1) to $85.87 \%$ (scenarios \#4 and \#5). This risk of failure in the accomplishment of the project makespan is evidenced by comparing the critical metrics; for the scenario \#1, the sum of total floats ( $\left.\sum \overline{T F}_{i}\right)$ is a positive fuzzy value $(216.0,1066.0$, 1939.0) which provides a buffer of security along the project. In scenario \# 5, ensuring the continuity for all the activities and processes, $\sum \overline{T F}_{i}$ is negative in his left side indicating greatest compliance risk. 
To check the goodness of the proposal, the scenario \#1 of the example of application has been scheduled and compared with Primavera (C) P6 Professional V8.2.0 (P6P). First (Solution A), the model has been solved considering the same activities/processes and the needed relationships for each algorithm that best considers the project restrictions. The project makespan provided by P6P is of 409 days versus 385 of the optimal makespan with fuzzy-GPSP (table 5); additionally, P6P presents 276 differences on scheduled times and 69 on float values of activities compared to the proposed fuzzy-GPSP. Later (Solution B), the model was scheduled with P6P without restrictions in the number of activities with the aim to obtain the same values provided by fuzzy-GPSP; for solution B, P6P required 78 activities with 137 relationships versus 18 activities/processes and 25 relationships needed with the fuzzy-GPSP.

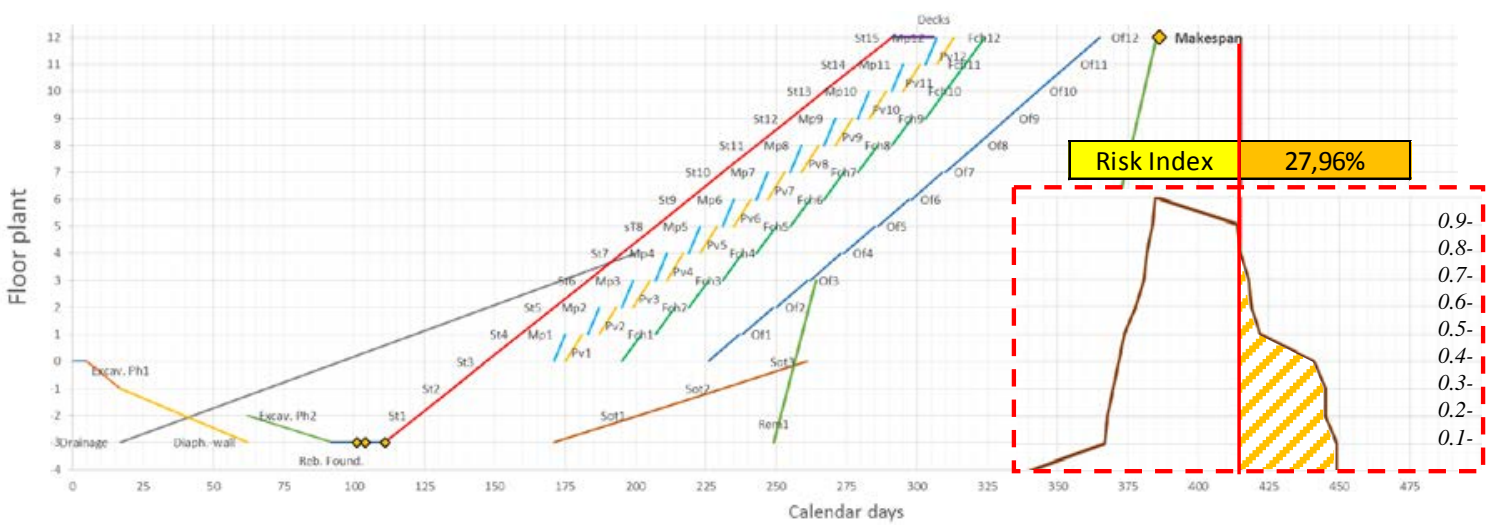

Fig. 15 Fuzzy makespan, risk index and space-time chart for scenario \#1

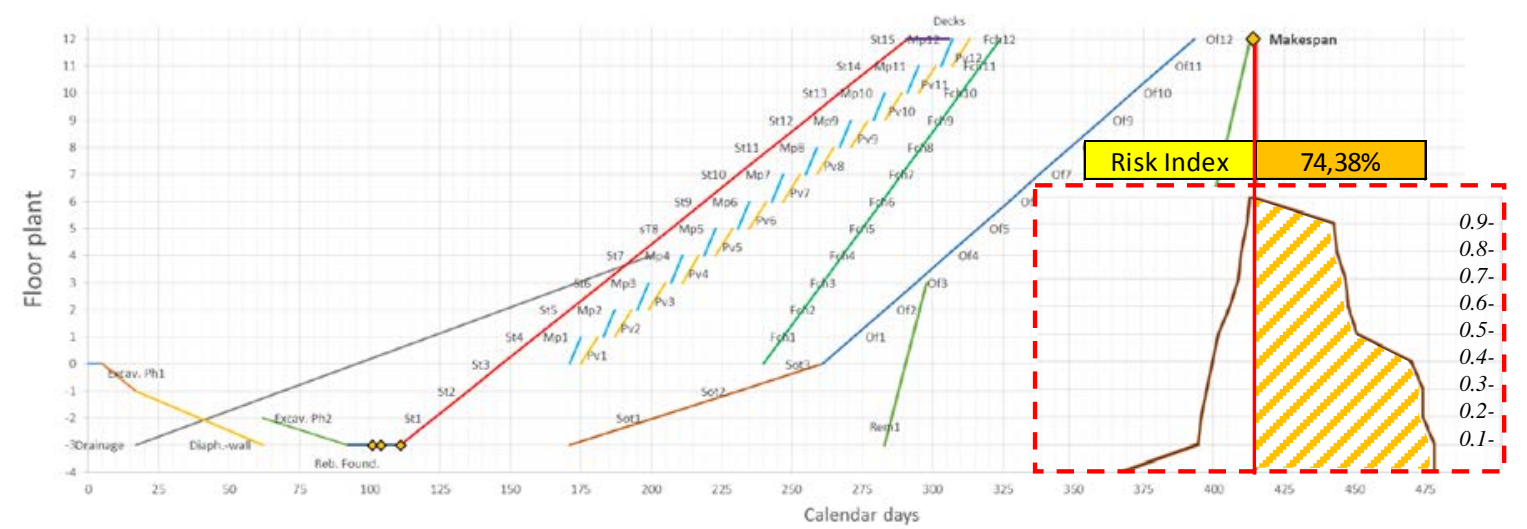

Fig. 16 Fuzzy makespan, risk index and space-time chart for scenario \#2

Table 5 Compared results for case 1with Primavera $\$ P6 Professional V8.2.0

\begin{tabular}{|c|c|c|c|c|c|c|c|c|}
\hline & & \multirow{2}{*}{ Model } & \multirow{2}{*}{ Activities } & \multirow{2}{*}{ Relationships } & \multirow{2}{*}{ Makespan } & \multirow{2}{*}{ Optimal } & \multicolumn{2}{|c|}{ Differences } \\
\hline & & & & & & & Time & Floats \\
\hline \multirow{3}{*}{ Scenario 1} & \multirow{2}{*}{ Solution A } & Fuzzy-GPSP & 18 & 25 & 385.0 & Yes & -- & -- \\
\hline & & Primavera 6 & 18 & 31 & 409.0 & No & 276 & 69 \\
\hline & Solution B & Primavera 6 & 78 & 137 & 385.0 & Yes & 0 & 0 \\
\hline
\end{tabular}

Then, to analyze the versatility of the fuzzy-GPSP, the number of operations needed in the transition from scenario \#1 to \#5 was computed (considering all the activities and processes continuous); the results are summarized in Table 6, comparing the obtained makespan and the number of differences in scheduled times and floats. P6P needed sixty operations versus the seven operations used by fuzzy-GPSP. Furthermore, the solution obtained with P6P is not an optimal solution, presenting 48 differences in scheduled times and 33 in floats compared to the proposed fuzzy-GPSP.
The scenario \#5 was selected as it provides the most unbiased analysis. The procedure used with P6P in order to guarantee the continuity of processes and activities is to establish the primary constraint of the activity status "As Late As Possible”, from the last activity to the first in topological order, consuming the free float of all the activities. With this procedure, the differences depend on the topological position in the graph, and they are reduced when all activities are considered in the analysis.

Table 6 Compared results for transition from scenario \#1 to scenario \#5

\begin{tabular}{ccccccccc}
\hline \multirow{2}{*}{ Model } & \multirow{2}{*}{ Activities } & \multirow{2}{*}{ Relationships } & \multirow{2}{*}{ Makespan } & \multirow{2}{*}{ \# Oper } & \multirow{2}{*}{ Optimal } & \multicolumn{2}{c}{ Differences } \\
\cline { 5 - 9 } Scenario 5 & Fuzzy-GPSP & 18 & 25 & 421.0 & 7 & Yes & -- & -- \\
& Primavera 6 & 78 & 137 & 385.0 & 60 & No & 48 & 33 \\
\hline
\end{tabular}


The fragmentation of construction activities and processes with many work intervals, restarts and interruptions is questionable from a practitioner's point of view. Continuity is desirable to reduce direct cost, but overlapping and fragmentation reduces the risk of accomplishment and the project makespan. The proposed model does not consider the cost of disruption because, in the authors' opinion, the benefits of improving the project makespan and reducing the risk of not accomplishment could be significantly more relevant than the cost of disruption. Nonetheless, it is discretional, and fairly straightforward, for schedulers to consider it in their decision-making.

The proposed fuzzy-GPSP is an important innovation on construction project scheduling, providing a robust and friendly decision support system, not only in its theoretical nature but in real life projects too. The limitations of the proposed model have to be analyzed more in-depth, although it has been tested with P6P as well as with some relevant problems identified in the literature that have been successfully solved, matching or improving their original solutions, despite the differences between them.

\section{CONCLUSIONS}

Scheduling of construction projects involves problems related to the overlapping of processes and activities, reverse criticality, fragmentation, continuity and the use of unavailable or incomplete information. These facts produce a high risk of failed forecasts where a realistic approach in imprecise scenarios is not totally solved. The algorithms proposed by previous researchers only cope with some kinds of Generalized Precedence Relations and partially fail to provide satisfactory solutions to long-term scheduling problems.

Therefore, with the aim of helping to fill this gap, this paper presents a heuristic approach to the Project Scheduling Problem with Precedence Relations applying the Theory of Fuzzy Sets, which allows the splitting of activities and considers the optimal processes flow. The compiled heuristic algorithm for the fuzzy-GPSP is presented in the pseudo-code 7 , being simpler than the existing ones and corrects the errors that other approaches have, especially by computing the latest times. It computes the fuzzy times, fuzzy floats, critical index, and critical value of activities and processes; it also calculates the risk of accomplishing the project makespan over the release date, plotting the fuzzy time for any of the activities by their ES, EF, LS, and LF. Additionally, it permits changes in the precision of the computations modifying the alphainterval, and the discretization of the fuzzy times in real days.

In order to test the performance of the model, it has been compared to previous algorithms proposed by other authors, discussing its capabilities. Furthermore, the model has been implemented in Visual Basic for Applications (Excel 2013) and applied to a building of 15 floors with a total of 18 activities/processes and 25 relationships, which summarizes 78 activities/subprocesses and 137 relationships, comparing the obtained schedules with Primavera (C) P6 Professional V8.2.0 in five different scenarios and transitions between them.

This paper contributes to the body of knowledge of construction project scheduling in several ways:

1. It comprises a complete state-of-knowledge of overlapping and splitting activities in the Project Scheduling Problem.

2. It presents a more realistic formulation of the fuzzy arithmetic for computing the latest starting times of the activities, which avoids the negative values.

3. It puts forward a fuzzy heuristic algorithm for the unconstrained case which improves and corrects previous contributions, computing unequivocally the fragmentation of activities.

4. It proposes a model for construction scheduling that takes into consideration all the feeding, work and time Generalized Precedence Relations, allowing the splitting of activities and continuity of processes in a discretionary way, as well as the balance of process flows.

5. The proposed model avoids the interruption of the critical path and the reverse criticality issue.

Schedulers and users can use the model in order to overcome some of the problems of the current algorithms, because these barely consider the complex and ill-defined conditions of construction projects. To begin with, the proposed algorithm handles all the feeding, work and time Generalized Precedence Relations and computes the fragmentation avoiding the interruption of the critical path. The model avoids reverse criticality by using feeding precedence relationships instead of the classical work days; this approach suits the natural thinking style of schedulers, who initially analyze and estimate the amounts, production flows and interdependences between activities. This anomaly implies that practitioners have to be alert if they use commercial software with Generalized Precedence Relations, when adjusting the project duration by modifying the duration of the critical path or in the process of rescheduling the project. This can provide incorrect schedules, with errors difficult to detect and resolve, especially with a great number of activities. Furthermore, this algorithm includes the balance of process flows, letting the scheduler to analyze the effects of overlapping and continuity of processes or activities over the makespan, as well as to deal with a single process instead of multiple different activities. Its implementation in a professional application can help practitioners to schedule real and complex projects in imprecise environments, modelling the project according to their needs and thinking style in an easy way, without having to adapt the real problem to the imposed relaxation of commercial software. 


\section{NOTATION}

The following concepts, symbols and acronyms are used in this article:

\begin{tabular}{|c|c|}
\hline Concepts, symbols and acronyms & Meaning \\
\hline $\bar{A}(x)=\{x, \mu(x) \mid x \in \Omega\} ; \bar{A}(x)=\left(a_{1}, a_{2}, a_{3}\right)$ & Fuzzy number of $\Omega$ (fuzzy set of real numbers) \\
\hline$\left[a_{1}, a_{3}\right]$ & Support of a fuzzy number (membership equals zero) \\
\hline$a_{2}$ & Vertex of a fuzzy number (membership equals one) \\
\hline$[A]^{\alpha}=\left[a_{1}(\alpha), a_{3}(\alpha)\right]$ & Alpha cut (alpha interval) of $\bar{A}(x)$ \\
\hline$\left[a_{1}(\alpha), a_{3}(\alpha)\right]=\left[a_{1}+\alpha \cdot\left(a_{2}-a_{1}\right), a_{3}+\alpha \cdot\left(a_{2}-a_{3}\right)\right]$ & Alpha interval calculation \\
\hline$[A]^{\alpha} \#[B]^{\alpha}=[C]^{\alpha}=\left[c_{1}(\alpha), c_{3}(\alpha)\right] ; \forall \alpha \mid 0 \leq \alpha \leq 1$ & Conceptual fuzzy arithmetic by intervals \\
\hline$c_{1}(\alpha)=\min \left(\begin{array}{l}a_{1}(\alpha) \# b_{1}(\alpha), \\
a_{1}(\alpha) \# b_{3}(\alpha), \\
a_{3}(\alpha) \# b_{1}(\alpha), \\
a_{3}(\alpha) \# b_{3}(\alpha)\end{array}\right) ; c_{3}(\alpha)=\max \left(\begin{array}{l}a_{1}(\alpha) \# b_{1}(\alpha), \\
a_{1}(\alpha) \# b_{3}(\alpha), \\
a_{3}(\alpha) \# b_{1}(\alpha), \\
a_{3}(\alpha) \# b_{3}(\alpha)\end{array}\right)$ & Fuzzy arithmetic by intervals \\
\hline $\begin{array}{c}\bar{C}(x) \geq\{\bar{A}(x), \bar{B}(x), \ldots, \bar{Z}(x)\} \\
\left\{\begin{array}{l}c_{1}(\alpha)=\max \left(a_{1}(\alpha), b_{1}(\alpha), \ldots, z_{1}(\alpha)\right) \\
c_{3}(\alpha)=\max \left(a_{3}(\alpha), b_{3}(\alpha), \ldots, z_{3}(\alpha)\right)\end{array}\right.\end{array}$ & $\begin{array}{l}\text { Fuzzy number } \bar{C}(x) \text { strictly greater than or equal to a } \\
\text { given set of fuzzy numbers }\end{array}$ \\
\hline $\begin{array}{c}\bar{C}(x) \leq\{\bar{A}(x), \bar{B}(x), \ldots, \bar{Z}(x)\} \\
\left\{\begin{array}{l}c_{1}(\alpha)=\min \left(a_{1}(\alpha), b_{1}(\alpha), \ldots, z_{1}(\alpha)\right) \\
c_{3}(\alpha)=\min \left(a_{3}(\alpha), b_{3}(\alpha), \ldots, z_{3}(\alpha)\right)\end{array}\right.\end{array}$ & $\begin{array}{l}\text { Fuzzy number } \bar{C}(x) \text { strictly less than or equal to a } \\
\text { given set of fuzzy numbers }\end{array}$ \\
\hline$C I_{j}$ & Critical index of $j$ \\
\hline$E F$ & Early finish \\
\hline$E S$ & Early start \\
\hline \begin{tabular}{l|l|l}
$F F_{i j}\left(p_{i}\right.$ & $w_{i}$ & $z)$ \\
\end{tabular} & Finish to finish relationship \\
\hline$F l_{i j}\left(p_{i}\left|p_{i}\right| z\right)$ & Flow relationship \\
\hline$F S_{i j}(\mathrm{z})$ & Finish to start relationship \\
\hline fuzzy-GPSP & Fuzzy project scheduling problem with GPRs \\
\hline GPRs & Generalized precedence relations \\
\hline GPSP & Project scheduling problem with GPRs \\
\hline$L F$ & Latest finish \\
\hline$L S$ & Latest start \\
\hline$P S P$ & Project scheduling problem \\
\hline P6P & Primavera (C P6 Professional V8.2.0 \\
\hline$R V$ & Risk value \\
\hline$S F_{i j}\left(p_{i}, w_{i}\left|p_{i}, w_{i}\right| z\right)$ & Start to finish relationship \\
\hline \begin{tabular}{l|l|l}
$S S_{i j}\left(p_{i}\right.$ & $w_{i}$ & $z)$ \\
\end{tabular} & Start to start relationship \\
\hline TF & Total float \\
\hline TFN & Triangular fuzzy number \\
\hline
\end{tabular}

\section{REFERENCES}

Adeli, H. \&. (1995). Optimization of Space Structures by Neural Dynamics. Neural Networks, 8(2), 769781.

Adeli, H., \& Karim, A. (1997). Scheduling/Cost Optimization and Neural Dynamics model for construction. Journal of Construction Engineering and Management, ASCE, 123(4), 450-458.

Adeli, H., \& Karim, A. (2001). Construction Scheduling, Cost Optimization, and Management: A New Model Based on Neurocomputing and Object Technologies (Vol. 8). London: Spon Press. doi:10.1046/j.1365-232X.2001.0190b.X

Adeli, H., \& Wu, M. (1998). Regularization neural network for construction cost estimation. Journal of Construction Engineering and Management, 124(1), 18-24.
Alarcón, L., Ashley, D., Sucre de Hanily, A., Molenaar, K., \& Ungo, R. (2011). Risk Planning and Management for the Panama Canal Expansion Program. Journal of Construction Engineering and Management, 137(10), 762-771.

Ammar, M. A. (2013). LOB and CPM Integrated Method for Scheduling Repetitive Projects. Journal of construction engineering and management, 44-50. doi:10.1061/(ASCE)CO.1943-7862.0000569

Arditi, A., \& Bentotage, S. (1996). System for Scheduling Highway Construction Projects. Computer-Aided Civil and Infrastructure Engineering, 11, 123-139.

Ballesteros-Pérez, P., González-Cruz, M., \& PastorFerrando, J. (2010). Analysis of Construction Projects by means of Value Curves. International Journal of Project Management, 28, 719-731. 
Barrie, G., \& Paulson, B. (1978). Profesional Construction Management. New York: McGraw-Hill Inc.

Bartusch, M., Möhring, R., \& Radermacher, F. (1988). Scheduling project networks with resource constraints and time windows. Annals of Operations Research, 16(1), 199-240. doi:10.1007/BF02283745

Bianco, L., \& Caramia, M. (2009). An Excat Algorithm to Minimize the makespan in Project Scheduling with Scarce Resources and Feeding Precedence Relations. RR-03.09 - University of Rome “Tor Vergata”, 210214. doi:hdl.handle.net/2108/912

Bianco, L., \& Caramia, M. (2011). Minimizing the completion time of a project under resource constraints and feeding precedence relations: a Lagrangian relaxation based lower bound. 4OR: A Quarterly Journal of Operations Research, 9(4), 371389. doi:10.1007/s10288-011-0168-6

Bianco, L., \& Caramia, M. (2012). Minimizing the completion time of a project under resource constraints and feeding precedence relations: an exact algorithm. 4OR: A Quarterly Journal of Operations Research, 1-17. doi:10.1007/s10288-012-0205-0

Bonnal, P., Gourc, D., \& Lacoste, G. (2004). Where Do We Stand with Fuzzy Project Scheduling? Journal of Construction Engineering and Management, 130(1), 114-123. doi:10.1061/(ASCE)0733-9364

Brunelli, M., \& Mezei, J. (2013). How different are ranking methods for fuzzy numbers? A numerical study. International Journal of Approximate Reasoning, 54, 627-639. doi:10.1016/j.ijar.2013.01.009

Buckley, J., \& Eslami, E. (2002). An Introduction to Fuzzy Logic and Fuzzy Sets. Sprnger.

Castro-Lacouture, D., Süer, G., Gonzalez-Joaqui, J., \& Yates, J. (2009). Construction project scheduling with time, cost, and material restrictions using fuzzy mathematical models and critical path method. Journal of Construction Engineering and Management, 135(10), 1096-1104.

Chanas, S., \& Kamburowski, J. (1981). The use of fuzzy variables in PERT. Fuzzy Sets and Systems, 5, 11-19.

Chang, I., Tsujimura, Y., Gen, M., \& Tozawa, T. (1995). An efficient approach for large scale project planning based on fuzzy Delphy method. Fuzzy Sets and Systems, 76, 277-288. doi:10.1016/01650114(94)00385-4

Chen, C.-T., \& Huang, S.-F. (2007). Applying fuzzy method for measuring criticality in project network. Information Sciences, 177(12), 2448-2458. doi:10.1016/j.ins.2007.01.035

Chen, S.-M., \& Chang, T.-H. (2001). Finding Multiple Possible Critical Paths Using Fuzzy PERT. IEEE Transaction on Systems, Man and Cybernetics- Part B:Cybernetics, 31(6), 930-937. doi:10.1109/3477.969496

Chrysafis, K., \& Papadopoulos, B. (2014). Possibilistic Moments for the Task Duration in Fuzzy PERT. Journal of Management in Engineering. doi: 10.1061/(ASCE)ME.1943-5479.0000296
Crandall, K. (1973). Project Planning with Precedence Lead/Lag Factors. Project Management Quarterly, 4, 18-27.

Damci, A., Arditi, A., \& Polat, G. (2013). Resource Leveling in Line-of-Balance Scheduling. ComputerAided Civil and Infrastructure Engineering, 28, 679692. doi:10.1111/mice. 12038

De Reyck, B., \& Herroelen, W. (1998). A branch-andbound procedure for the resource-constrained project scheduling problem with generalized precedence relations. European Journal of Operations research, 111(1), 152-174. doi:10.1016/S0377-2217(97)003056

De Reyck, B., \& Herroelen, W. (1999). The multimode resource-constrained project scheduling problem with generalized precedence relations. European Journal of Operational Research, 119, 538556. doi:10.1016/S0377-2217(99)00151-4

Demeulemeester, E., \& Herroelen, W. (2002). Project Scheduling: A Research Handbook Vol. 49 International Series in Operations Research \& Management Science. Springer.

Deng, H. (2014). Comparing and ranking fuzzy numbers using ideal solutions. Applied Mathematical Modelling, 38, doi:10.1016/j.apm.2013.09.012

Dubois, D., Fargier, H., \& Galva, V. (2003). On latest starting times and floats in activity networks with illknown durations. European Journal of Operational Research, 147(2), 266-280.

Elmaghraby, S., \& Kamburowski, J. (1992). The analysis of activity networks under generalizaed precedence ralations (GPRs). Management Science, 38(9), 1245-1256.

Fondahl, J. W. (1961). A Non-Computer Approach to the Critical Path Method for the Construction Industry. Department of Civil Engineering, Stanford University.

Gil-Aluja, J. (2004). Fuzzy Sets in the Management of Uncertainty. Berlin Heidelberg: Springer.

Hajdu, M. (1996). Splitting Allowed. In Network Scheduling Techniques for Construction Project Management (p. 162). Springer.

Haque Khan, A., \& Akhtar Hasin, A. (2012). Genetic algorithm for project time-cost optimization in fuzzy environment. Journal of Industrial Engineering and Management, 5(2), 364-381. doi:10.3926/jiem.410

Harris, R. B., \& Ioannou, P. G. (1988). Scheduling projects with repeating activities. Journal of Construction Engineering and Management, 124(4), 269-278. doi:10.1061/(ASCE)0733-9364

Hejducki, Z. (2004). Sequencing Problems in Methods of Organising Construction Processes. Engineering, Construction and Architectural Management, 11, 2032.

Herbert, J., \& Deckro, R. (2011). Combining Contemporary and Traditional Project Management Tools to Resolve a Project Scheduling Problem. Computers \& Operations Research, 38, 21-32.

Herroelen, W., \& Leus, R. (2005). Project Scheduling under Uncertainty: Survey and Research Potentials. 
European Journal of Operational Research, 165, 289306.

IBM. (1968). Project Management System, Application Description Manual (H20-0210).

Karim, A., \& Adeli, H. (1999a). Object-Oriented Information Model for Construction Project Management. Journal of Construction Engineering and Management, 125(5), 361-367.

Karim, A., \& Adeli, H. (1999b). CONSCOM: An OO Construction Scheduling and Change Management System. Journal of Construction Engineering and Management, 125(5), 368-376.

Karim, A., \& Adeli, H. (1999c). A new generation software for construction scheduling and management. Engineering, Construction and Architectural Management, 6(4), 380-390.

Kelley, J. J., \& Walker, M. R. (1959). Critical-Path Planning and Scheduling. Proceedings of the eastern joint computer conference, 160-173.

Kerbosch, J., \& Schell, H. (1975). Network Planning by the extended metra potential method (EMPM). Reports KS - 1.1 Department of Industrial Engineering, Group Operational research, University of Technology Eindhoven, 1-15.

Kim, S.-G. (2012). CPM Schedule Summarizing Function of the Beeline Diagramming Method. Journal of Asian Architecture and Building Engineering, 11(2), 367-374.

Kis, T. (2005). A branch-and-cut algorithm for scheduling of projects with variable-intensity activities. Math program, 103(3), 515-539. doi:10.1007/s10107-004-0551-6

Kis, T. (2006). Rcps with variable intensity activities and feeding precedence constraints. In Perpectives in modern project scheduling (pp. 105-129). USA: Springer. doi:10.1007/978-0-387-33768-5_5

Kis, T., Erdös, G., \& Márkus, A. (2004). A projectoriented decision support system for production planning in make-to-order manufacturing. ERCIM news, 58, 66-67.

Kolisch, R., \& Sprecher, A. (1996). PSPLIB -- A project scheduling problem library. European Journal of Operational Research, 96, 205-216. doi:10.1016/S0377-2217(96)00170-1

Krishnan, V., Eppinger, S., \& Whitney, D. (1997). A Model-Based Framework to Overlap Product Development Activities. Management Science, 43(4), 437-451. doi:10.1287/mnsc.43.4.437

Leachman, R. C., Dtncerler, A., \& Kim, S. (1990). Resource-Constrained Scheduling of Projects with Variable-Intensity Activities. IIE Transactions, 22(1), 31-40. doi:10.1080/07408179008964155

Lim, T., Yi, C., Lee, D., \& Arditi, D. (2014). Concurrent Construction Scheduling Simulation Algorithm. Computer-Aided Civil and Infrastructure Engineering, 29, 449-463.

Lino, P., Pérez, Á., Quintanilla, S., \& Valls, V. (2012). A study of generalised precedence relationships in project scheduling. 13th International Conference on Project Management and Scheduling, (pp. 215-218). Leuven.
Long, L., \& Ohsato, A. (2006). Fuzzy critical chain method for project scheduling under resource constraints and uncertainty. International Journal of Project Management, 26(6), 688.

Lootsma, F. (1989). Stochastic and fuzzy Pert. European Journal of Operational Research, 43(2), 174-183. doi:10.1016/0377-2217(89)90211-7

Lopez, P., \& Roubellat, F. (2013). Production Scheduling. John Wiley \& Sons.

Ma, G., Gu, L., \& Li, N. (2015). Scenario-Based Proactive Robust Optimization for Critical-Chain Project Scheduling. J. Constr. Eng. Management. doi:10.1061/(ASCE)CO.1943-7862.0001003

Malcolm, D., Roseboom, J., Clark, C., \& Fazar, W. (1959). Application of a technique for research and development program evaluation. Operations Research, 7(5), p646, 24p. doi:10.1287/opre.7.5.646

Maravas, A., \& Pantouvakis, J. (2011a). Fuzzy Repetitive Scheduling Method for Projects with Repeating Activities. Journal of Construction Engineering and Management, 137(7), 561-564. doi:10.1061/(ASCE)CO.1943-7862.0000319

Maravas, A., \& Pantouvakis, J. P. (2011b). A process for the estimation of the duration of activities in fuzzy project scheduling. The ICVRAM 2011 and ISUMA 2011 Conferences: Vulnerability, Uncertainty, and Risk@ sAnalysis, Modeling, and Management. ASCE, (pp. 62-69).

Moder, J., Philips, C., \& Davis, E. (1983). Project Management with CPM, PERT and Precedence Diagramming (3rd Edition ed.). New York: Van Nostrand Reinhold.

Nicholas, J., \& Steyn, H. (2008). Project Management for Business, Engineering, and Technology (3rd Edition ed.). Burlington (Massachussets): Butterworth-Heinemann.

O’Brien, J. (1969). Scheduling handbook. New York, N.Y.: McGraw-Hill Inc.

O’Brien, J. (1975). VPM scheduling for high-rise buildings. J. Constr. Div., 101(4), 895--905.

Ponz-Tienda, J., Benlloch-Marco, J., Andrés-Romano, C., \& Gil-Senabre, D. (2011). Un algoritmo matricial RUPSP / GRUPSP "sin interrupción" para la planificación de la producción bajo metodología Lean Construction basado en procesos productivos. Revista de la Construcción, 10(1), 90-103. doi:10.4067/S0718-915X2011000200009

Ponz-Tienda, J., Pellicer, E., \& Yepes, V. (2012, 1 1). Complete fuzzy scheduling and fuzzy earned value management in construction projects. Journal of Zhejiang University - Science A Issn: 1673-565X, 13(1), 56-68. doi:10.1631/jzus.A1100160

Ponz-Tienda, J., Yepes, V., Pellicer, E., \& MorenoFlores, J. (2013). The Resource Leveling Problem with multiple resources using an adaptive genetic algorithm. Automation in Construction, 29(0), 161172. doi:10.1016/j.autcon.2012.10.003

Prade, H. (1979). Using fuzzy set theory in a scheduling problem: A case study. Fuzzy Sets and Systems, 2, 153-165.

Quintanilla, S., Pérez, Á., Lino, P., \& Valls, V. (2012). Time and work generalised precedence relationships 
in project scheduling with pre-emption: An application to the management of Service Centres. European Journal of Operational Research, 219, 5972. doi:10.1016/j.ejor.2011.12.018

Rommelfanger, H. (1994). Network analysis and information flow in fuzzy environment. Fuzzy Sets and Systems, 67(1), 119-128.

Roy, B. (1962). Graphes et ordonnancements. Revue Fran aise de recherche operationelle, 25(6), 323.

Schwindt, C. (2014). Project Scheduling Under Generalized Precedence Relations. A Survey of Structural Issues, Solution Approaches, and Applications. In T. Fliedner, R. Kolisch, \& A. Naber (Ed.), 14th International Conference on Project Management and Scheduling (p. Plenary talk). Munich, Germany: TUM School of Management. Retrieved from https://goo.gl/XXSJ62

Senouci, A. B., \& Adeli, H. (2001). Resource scheduling using neural dynamics model of Adeli and Park. Journal of Construction Engineering and Management, 127(1), 28-34.

Seppänen, O., Evinger, J., \& Mouflard, C. (2014). Effects of the location-based management system on production rates and productivity. Construction Management and Economics, 32(6), 608-624.

Shi, Q., \& Blomquist, T. (2012). A new approach for project scheduling using fuzzy dependency structure matrix. International Journal of Project Management, 30(4), 503-510. doi:10.1016/j.ijproman.2011.11.003

Srour, I., Abdul-Malak, M.-A., Yassine, A., \& Ramadan, M. (2013). A methodology for scheduling overlapped design activities based on dependency information. Automation in Construction, 29, 1-11. doi:10.1016/j.autcon.2012.08.001

Stradal, O., \& Cacha, J. (1982). Time space scheduling method. J. Constr. Div. ASCE, 108(3), 445-457.

Valls, V., \& Lino, P. (2001). Criticality Analysis in Activity-on-Node Networks with Minimal Time Lags. Annals of Operations research, 102, 17-37. doi:10.1023/A:1010941729204

Valls, V., Martí, R., \& Lino, P. (1996). A Heuristic Algorithm for Project Scheduling with Splitting Allowed. Journal of Heuristcs, 2(1), 87-104. doi:10.1007/BF00226294

Wang, Y.-M., Yang, J.-B., Xu, D.-L., \& Chin, K.-S. (2006). On the centroids of fuzzy numbers. Fuzzy Sets and Systems, 157, 919-926. doi:10.1016/j.fss.2005.11.006

Wiest, J. (1981). Precedence Diagramming method: Some Unusual Characteristics And Their Implications For Project Managers. Journal of Operations Management, 1(3), 121-130. doi:10.1016/02726963(81)90015-2

Zadeh, L. (1965). Fuzzy Sets. Information and Control, 8, 338-353. doi:10.1016/S0019-9958(65)90241-X 